\title{
Separation of low and high grade colon and rectum carcinoma by eukaryotic translation initiation factors 1, 5 and 6
}

This article has been corrected. Correction in: Oncotarget. 2023; 14:83-84.

Nicole Golob-Schwarzl ${ }^{1,2}$, Caroline Schweiger ${ }^{1}$, Carina Koller ${ }^{1}$, Stefanie Krassnig ${ }^{1}$, Margit Gogg-Kamerer ${ }^{1}$, Nadine Gantenbein ${ }^{1,2}$, Anna M. Toeglhofer ${ }^{1}$, Christina Wodlej $^{1,2}$, Helmut Bergler ${ }^{3}$, Brigitte Pertschy ${ }^{3}$, Stefan Uranitsch ${ }^{4}$, Magdalena Holter $^{5}$, Amin El-Heliebi ${ }^{6}$, Julia Fuchs ${ }^{6}$, Andreas Punschart ${ }^{7}$, Philipp Stiegler ${ }^{7}$, Marlen Keil ${ }^{8}$, Jens Hoffmann ${ }^{8}$, David Henderson ${ }^{9}$, Hans Lehrach ${ }^{10}$, Christoph Reinhard ${ }^{11}$, Christian Regenbrecht ${ }^{12}$, Rudolf Schicho ${ }^{13}$, Peter Fickert ${ }^{14}$, Sigurd Lax $^{15}$ and Johannes Haybaeck ${ }^{1,2,16}$

\footnotetext{
${ }^{1}$ Institute of Pathology, Medical University of Graz, Graz, Austria

${ }^{2}$ Center for Biomarker Research in Medicine, Graz, Austria

${ }^{3}$ Institute of Molecular Biosciences, Karl-Franzens-University of Graz, Graz, Austria

${ }^{4}$ Department of Surgery, Hospital Brothers of Charity Graz, Graz, Austria

${ }^{5}$ Institute of Medical Informatics, Statistics and Documentation, Medical University of Graz, Graz, Austria

${ }^{6}$ Institute of Cell Biology, Histology and Embryology, Medical University Graz, Graz, Austria

${ }^{7}$ Department of Surgery, Medical University of Graz, Graz, Austria

${ }^{8}$ Experimental Pharmacology \& Oncology Berlin GmbH-Berlin-Buch, Berlin, Germany

${ }^{9}$ Bayer AG, Berlin, Germany

${ }^{10}$ Max Planck Institute for Molecular Genetics, Berlin, Germany

${ }^{11}$ Eli Lilly \& Company, Indianapolis, USA

${ }^{12}$ Cpo - cellular phenomics \& oncology Berlin-Buch GmbH, Berlin, Germany

${ }^{13}$ Institute of Experimental and Clinical Pharmacology, Medical University of Graz, Graz, Austria

${ }^{14}$ Division of Gastroenterology and Hepatology, Medical University of Graz, Graz, Austria

${ }^{15}$ Department of Pathology, Hospital Graz South-West, Austria

${ }^{16}$ Department of Pathology, Otto-von-Guericke-University Magdeburg, Magdeburg, Germany

Correspondence to: Johannes Haybaeck, email: johannes.haybaeck@med.ovgu.de

Keywords: colorectal carcinoma; liver metastases; eukaryotic translation initiation factors; PI3K/AKT/mTOR pathway
}

Received: January 05, $2017 \quad$ Accepted: July 31, $2017 \quad$ Published: September 05, 2017

Copyright: Golob-Schwarzl et al. This is an open-access article distributed under the terms of the Creative Commons Attribution License 3.0 (CC BY 3.0), which permits unrestricted use, distribution, and reproduction in any medium, provided the original author and source are credited.

\section{ABSTRACT}

Colorectal cancer (CRC) is the third most common cause of cancer related death worldwide. Furthermore, with more than 1.2 million cases registered per year, it constitutes the third most frequent diagnosed cancer entity worldwide. Deregulation of protein synthesis has received considerable attention as a major step in cancer development and progression. Eukaryotic translation initiation factors (eIFs) are involved in the regulation of protein synthesis and are functionally linked to the phosphatidylinositol-3-kinase (PI3K)/AKT/mammalian target of rapamycin (mTOR) signaling pathway.

The identification of factors accounting for colorectal carcinoma (CRC) development is a major gap in the field. Besides the importance of eIF3 subunits and the eIf4 complex, eIF1, eIF5 and eIF6 were found to be altered in primary and 
metastatic CRC. We observed significant difference in the expression profile between low and high grade CRC. eIF1, eIF5 and eIF6 are involved in translational control in CRC. Our findings also indicate a probable clinical impact when separating them into low and high grade colon and rectum carcinoma.

eIF and $m$ TOR expression were analysed on protein and mRNA level in primary low and high grade colon carcinoma (CC) and rectum carcinoma (RC) samples in comparison to non-neoplastic tissue without any disease-related pathology. To assess the therapeutic potential of targeting eIF1, eIF5 and eIF6 siRNA knockdown in HCT116 and HT29 cells was performed. We evaluated the eIF knockdown efficacy on protein and mRNA level and investigated proliferation, apoptosis, invasion, as well as colony forming and polysome associated fractions.

These results indicate that eIFs, in particular eIF1, eIF5 and eIF6 play a major role in translational control in colon and rectum cancer.

\section{INTRODUCTION}

Colorectal cancer (CRC) is the third most common cause of cancer related death and with more than one million cases annually the third most frequently diagnosed cancer entity worldwide [1-3]. Major risk factors include high fat intake, alcohol, red meat, obesity, smoking, age and physical inactivity $[4,5]$. Approximately $20 \%$ of CRC patients have liver metastases at the time of diagnosis and $60 \%$ of patients develop liver metastases during the course of disease [6-8]. Current clinical management strategies include surgery, chemotherapy, radiation and palliative care, but they are not as effective as previously expected [4]. Various drugs have been reported to be effective against primary or metastatic CRC, but still the efficacy of current medications needs to be further improved. Although biologically similar, it needs to be taken into account, that carcinomas of the colon (CC) and rectum (RC) are treated differently with respect to surgery and radiotherapy [9].

Deregulation of protein synthesis has received considerable attention as a major step in cancer development and progression [10]. Protein synthesis is regulated at multiple stages, including translation of mRNA into proteins (Figure 1). Studies suggest that ribosomal protein synthesis plays a direct role during tumor initiation. Translation can be divided into 4 stages, namely initiation, elongation, termination, and ribosomal recycling, of which initiation is the rate-limiting step of protein synthesis in eukaryotes. The process of translation initiation starts with the formation of a $43 \mathrm{~S}$ pre-initiation complex composed of the 40S small ribosomal subunit, methionine tRNAi and a group of eukaryotic inititation factors (eIFs) (Figure 1). Subsequently, this $43 \mathrm{~S}$ pre-initiation complex binds to the 5' end of mRNA and then to eIF4F. Besides the eIF4F complex, other eIFs such as eIF1, eIF5, eIF6 and the large eIF3 complex comprising multiple subunits are involved in the initial translation regulation [10]. eIF1 is an essential mediator of start codon recognition and acts as negative regulator. eIF5 contains an unusual amino acid hypusine, which is important for eukaryotic cell proliferation. Two isoforms of eIF5 with high sequence homology undergo hypusination at the same specific lysine residue [11]. The expression of eIF5 has been shown to be upregulated in many cancer entities [12] and is thought to play a role in the regulation of cell proliferation and apoptosis [13]. Nevertheless, the exact mechanistic role of eIF5 in tumorigenesis is unknown.

The interaction of eIF1 and eIF3C has been shown in vitro and is essential for the recruitment of eIF 1 to the $40 \mathrm{~S}$ ribosomal subunit by eIF3 during initiation of protein translation [14].

eIF6 is mostly in the cytoplasm (although a minor pool is essential for nucleolar maturation of $60 \mathrm{~S}$ subunits), and has anti-association property, by blocking premature $60 \mathrm{~S}$ joining to 40S (Figure 1) [15-20]. eIF6 was found to be overexpressed in some cancer types, particularly in metastatic CRC [21].

We investigated the expression of members of the eIF family, focusing on eIF1, eIF5, and eIF6, together with components of the mammalian target of rapamycin (mTOR) signaling cascade. We analyzed the expression levels in primary low and high grade $\mathrm{CC}$ and $\mathrm{RC}$ as well as their liver metastases and corresponding non-neoplastic colorectal mucosa tissues (NNT). Finally, we assessed the therapeutic potential of targeting eIFs by performing siRNA knockdown experiments for eIF1, eIF5 and eIF6 in two CRC cell lines (HCT116, HT29).

\section{RESULTS}

\section{High expression of eIF1, eIF5 and eIF6 predicts poor prognosis of human CRC}

The TCGA database was investigated to identify mTOR members and eIF genes that are significantly altered in CRC. Kaplan-Meier curves were drawn to assess a potential association of mTOR members and eIF expression and overall survival in $\mathrm{CC}$ and $\mathrm{RC}$ patients. The median mTOR and eIF mRNA expression in all $\mathrm{CC}$ and $\mathrm{RC}$ tissues was used as the cutoff point to divide all cases into low and high grade CC $(n=201)$ and $R C(n=70)$ groups. As shown in Figure 2A there was a significant 
difference in the survival between patients of low and high grade CC for eIF1 $(\mathrm{p}=0.013)$, eIF5 $(\mathrm{p}=0.019)$ and eIF6 $(\mathrm{p}$ $=0.015$ ). However, gene expression of eIF1, eIF5 and eIF6 had no significant influence on overall survival between low and high grade $\mathrm{RC}$ patients (Figure $2 \mathrm{~B}$ and $2 \mathrm{C}$ ).

Additionally, to eIF1,5 and 6 also other eIF subunits were investigated regarding their influence on overall survival. As shown in Supplementary Figure 5A-5F, there was a significant difference in the survival between patients of low and high grade CC for eIF2S1 $(p=0.024)$, eIF3A $(p=0.011), \operatorname{eIF} 3 \mathrm{~B}(p=0.013), \operatorname{eIF} 3 \mathrm{C}(\mathrm{p}=0.013), \operatorname{eIF} 3 \mathrm{D}$ $(p=0.022)$ and $\operatorname{eIF} 3 \mathrm{H}(p=0.024)$ group. There were no significant differences in overall survival between RC low and high grade groups (Supplementary Figure 6A 6E) for eIF2S1, eIF3A, eIF3B, eIF3C, eIF3D and eIF3H. In Supplementary Figure 7A - 7F, there was a significant difference in the survival between patients of low and high grade CC for eIF3I ( $p=0.008)$, eIF3J ( $p=0.026)$, eIF3K ( $p$ $=0.006), \operatorname{eIF} 3 \mathrm{M}(\mathrm{p}=0.018), \operatorname{eIF} 4 \mathrm{~B}(\mathrm{p}=0.004)$ and eIF4E $(p=0.003)$ group. There were no significant differences in overall survival between low and high grade RC groups (Supplementary Figure 8A - 8E) for those genes. Besides for eIF3M ( $p=0.018)$. In Supplementary Figure 9A - 9C, there was a significant difference in the survival between patients of low grade and high grade CC for eIF4G1 (p $=0.005)$, eIF4G2 $(p=0.011)$, and eIF4G3 $(p=0.011)$ group. There were no significant differences for eIF4G1 and eIF4G3, for eIF4G2 $(p=0.011)$ there was a significant difference in the survival between low and high grade RC groups (Supplementary Figure 10).

To also investigate the influence of upstream signaling, also mTOR cascade members and their influence on overall survival of CRC patients. As shown in Supplementary Figure $1 \mathrm{~A}-1 \mathrm{~F}$, there was a significant difference in the survival between patients of low and high grade CC for mTOR $(\mathrm{p}=<0.001)$, PTEN $(\mathrm{p}=0.016)$, p70S6K $(p=0.016)$, AKT1 $(p=0.020)$, AKT2 $(p=0.024)$ and AKT3 $(p=0.021)$ group, but there were no significant differences in overall survival between low and high grade RC groups (Supplementary Figure 2A - 2F) for mTOR, PTEN, p70S6K, AKT1, AKT2 and AKT3 group. As shown in Supplementary Figure 3A-3E, there was a significant difference in the survival between patients of low and high grade CC for AMPK1 $(\mathrm{p}=<0.010)$, AMPK $(\mathrm{p}=$ $0.011)$, Rictor $(p=0.017)$, Raptor $(p=0.016)$ and RPS6 $(p=0.019)$ group. There were no significant differences in overall survival between RC low and high grade groups (Supplementary Figure 4A - 4E) for the mentioned genes. To summarize the results from the overall survival analyses, eIF1, eIF5, eIF6 as well as other eIF subunits and PI3K/ AKT/mTOR pathway members had a significant influence on the overall survival of $\mathrm{CC}$ and $\mathrm{RC}$ patients. This

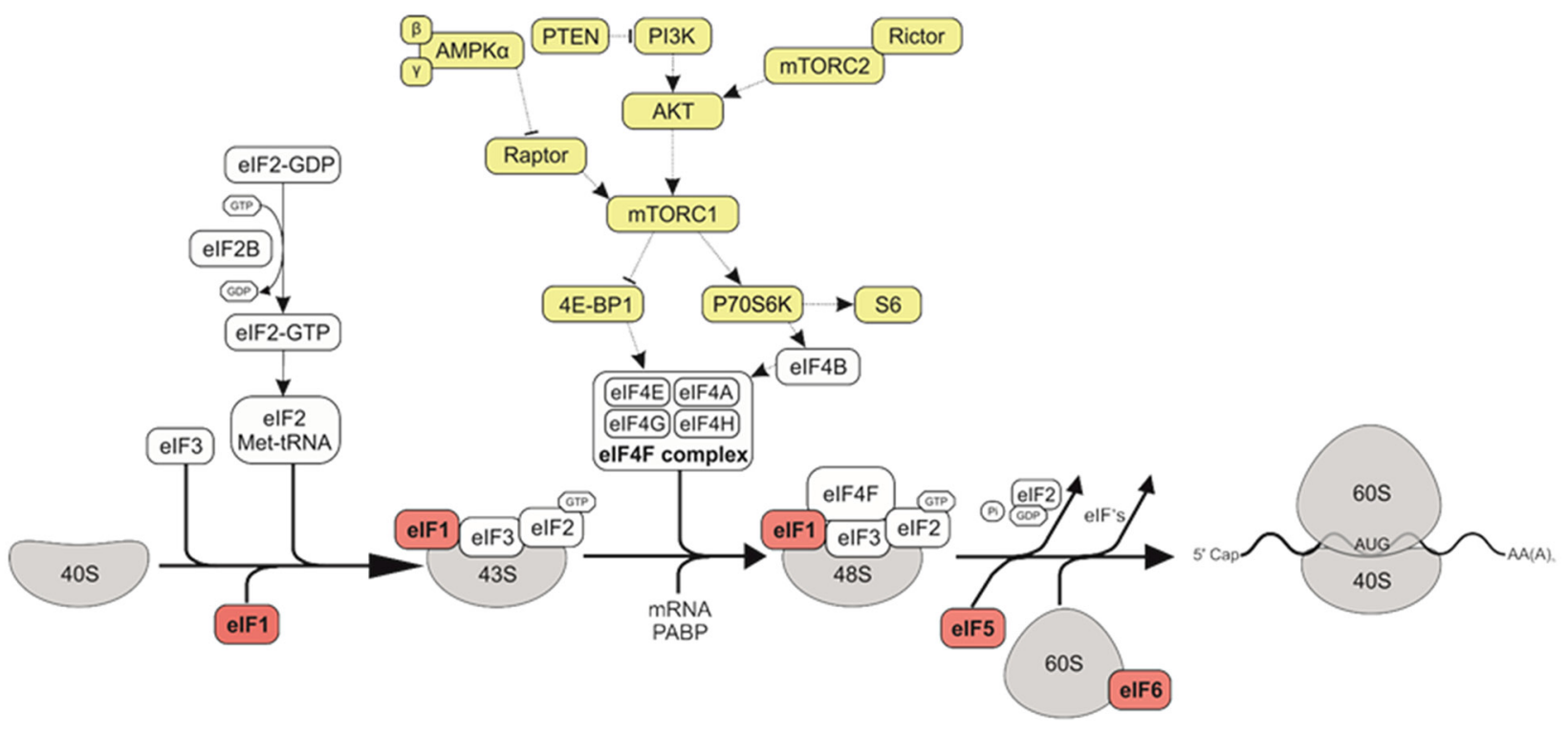

Figure 1: The role of eIF1, eIF5 and eIF6 in CRC. The eukaryotic translation initiation starts with the separation of 40S and 60S ribosomal subunits, and formation of an $80 \mathrm{~S}$ ribosomal initiation complex. Formation of a $43 \mathrm{~S}$ preinitiation complex comprising a $40 \mathrm{~S}$ subunit, eIF1, eIF1A, eIF3, eIF2-GTP-Met-tRNA ${ }_{i}^{\text {Met }}$ and probably eIF5. The next step is mRNA activation, followed by attachment of the $43 \mathrm{~S}$ complex to the activated mRNA region. Scanning of the $5^{\prime}$ UTR by $43 \mathrm{~S}$ complex. Recognition of the initiation codon and $48 \mathrm{~S}$ initiation complex formation. The next step is joining of 60S subunits to $48 \mathrm{~S}$ complexes and concomitant displacement of eIF2-GDP and other factors (eIF1, eIF3, eIF4B, eIF4F and eIF5). GTP hydrolysis by eIF5B and release of eIF1A and GDP-bound eIF5B. Termination follows elongation and leads to recycling. 
strengthens our hypothesis, that low and high grade tumors should be separated due to their molecular differences in eIF and mTOR signaling pathways.

\section{eIF expression is a marker in low and high grade $\mathrm{CC}$ and RC}

We first performed a basic characterization of eIFs on protein and mRNA level in CRC samples compared to NNT (Figure 3 and 4). For this purpose we separated CC and $\mathrm{RC}$ into low and high grade tumors and performed immunoblots and qRT-PCR.

peIF $2 \alpha$, eIF $2 \alpha$, eIF3A, eIF3B, eIF3C, eIF3H, eIF3J, eIF3M, eIF4A, peIF4B, eIF4B, eIF4E and eIF4G showed higher protein expression in $\mathrm{CRC}$ tumors in comparison to NNT (Figure 3A and Supplementary Figure 11).

To evaluate the gene expression at the mRNA level, we performed qRT-PCR and measured the transcripts of $13 \mathrm{eIFs}$ by relative quantification normalized to $\beta$-actin. Our results show that transcripts for the eIFs $1,2 \alpha, 3 A, 3 B, 3 C, 3 H, 3 J$, $3 M, 4 B, 4 G, 5$ and 6 showed a significant overexpression in CRC compared to NNT (Figure 3B, Supplementary Tables 1, 2 and 3). The mRNA expression of several eIF subunits differed between CC and RC. Interestingly, peIF $2 \alpha$, eIF $2 \alpha$ and the eIF3 initiation factors A, B, C, H and I as well as peIF4B, eIF4G, and eIF6 displayed a higher protein expression relative to NNT and RC compared to CC (Figure 3A, Supplementary Figure 11 and Supplementary Figure 12). eIF1, eIF4B and eIF5 showed increased protein levels in CC and RC compared to NNT (Figure 3A, Figure 4A, Supplementary Figure 11 and Supplementary Figure 12).

Furthermore, eIF1, eIF $2 \alpha, e I F 3 A$, eIF $3 B, e I F 3 C$, eIF3H, eIF3J, eIF3M, eIF4B, eIF4G and eIF6 showed a significantly higher mRNA expression level in $\mathrm{CC}$ compared to NNT (Figure 3B). For RC patients, we observed mRNA overexpression for the eIFs $1,2 \alpha, 3 A$, $3 B, 3 C, 3 H, 3 J, 3 M, 4 B, 4 G, 5$ and 6 (Figure $3 \mathrm{~B}$ and Figure 4B) compared to NNT.
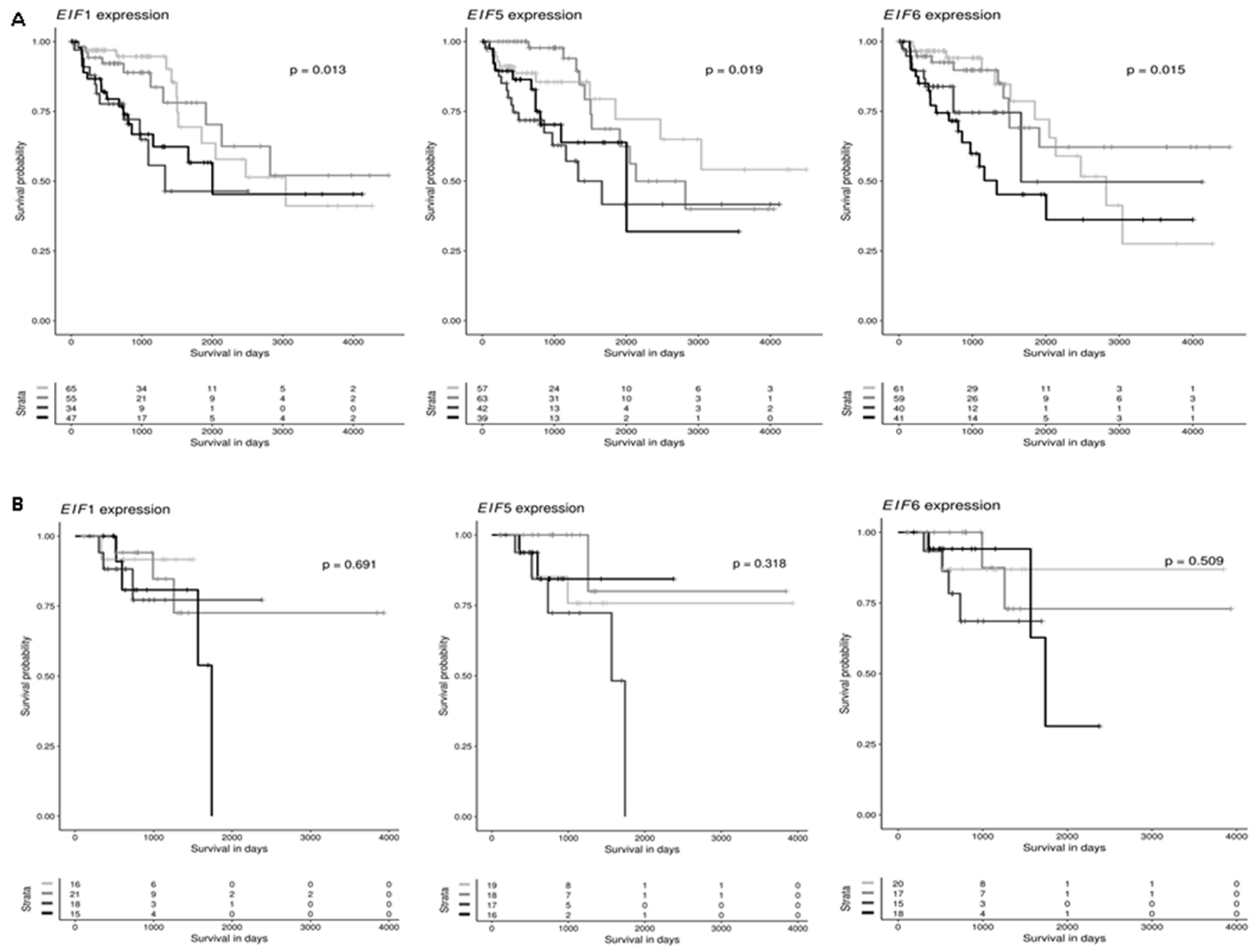

Figure 2: eIF1, eIF5 and eIF6 are clinically relevant candidates in CRC. (A) Kaplan-Meier curves reflect the effect of eIF1, eIF5 and eIF6 expression on overall survival for CC. Cases are divided in eIF1, eIF5 and eIF6 low or high expressers according to whether expression is below or above median and survival is compared using the log-rank test. (B) Kaplan-Meier curves reflect the effect of eIF1, eIF5 and eIF6 expression on overall survival for RC. Cases are divided in eIF1, eIF5 and eIF6 low or high expressers according to whether expression is below or above median and survival is compared using the log-rank test. 
As we noticed major differences in the protein expression between $\mathrm{CC}$ and $\mathrm{RC}$ patients, we decided to separate the results into low and high grade tumors. In low grade $\mathrm{CC}$, we observed an overexpression of eIF1 and eIF4B on protein level and in high grade $\mathrm{CC}$ only an overexpression of eIF1 (Figure 3A, Figure 4A, Supplementary Figure 11 and Supplementary Figure 12). The eIFs $1,2 \alpha, 3 A, 3 C, 3 H$, $3 J, 3 M, 4 B, 4 G$ and 6 (Figure $3 \mathrm{~B}$ and Figure $4 \mathrm{~B}$ ) showed a significant overexpression on mRNA level in low grade $\mathrm{CC}$ tumors. In contrast, the eIFs $1,3 B, 3 C, 3 H, 3 M, 4 B$ and 6 (Figure 3B and Figure 4B) revealed a significantly higher expression in high grade $\mathrm{CC}$ tumors.

However, in low grade $\mathrm{RC}$ the protein expression levels of the eIFs $1, \mathrm{p} 2 \alpha, 2 \alpha, 3 \mathrm{~A}, 3 \mathrm{C}, \mathrm{p} 4 \mathrm{~B}, 4 \mathrm{G}, 5$ and 6 were significantly increased relative to NNT compared to low grade CC (Figure 3A, Figure 4A, Supplementary Figure 11 and Supplementary Figure 12). Increased mRNA expression levels of eIFs $1,2 \alpha, 3 A, 3 B, 3 C, 3 H, 3 J, 4 B, 4 G, 5$ and 6 (Figure 3B, and Figure 4B) were observed in low grade RC.
Increased protein expression levels of eIF1, eIF $2 \alpha$, eIF3A, eIF3B, eIF3C, eIF3I, eIF3H, peIF4B, eIF4B, eIF4E, eIF5 and eIF6 (Figure 3A, Figure 4A, Supplementary Figure 11 and Supplementary Figure 12) were observed in high grade RC. In high grade RC the eIFs $1,2 \alpha, 3 A, 3 B, 3 C, 3 H, 3 J, 3 M, 4 B$, $4 G, 5$ and 6 (Figure 3B and Figure 4B) showed a significantly higher mRNA expression relative to NNT compared to high grade CC (Supplementary Tables 4 and 5).

\section{Silencing of eIF1, eIF5 and eIF6 in HCT116 cells and HT29 cells}

Based on the results of the eIF basic characterization in CRC patients (Figure 3, Figure 4, Supplementary Figure 11 and Supplementary Figure 12), eIF1, eIF5 and eIF6 were identified as novel factors, which are significantly activated in CRC (Supplementary Tables 1 and 2) and might therefore represent potential targets for future therapeutic intervention.
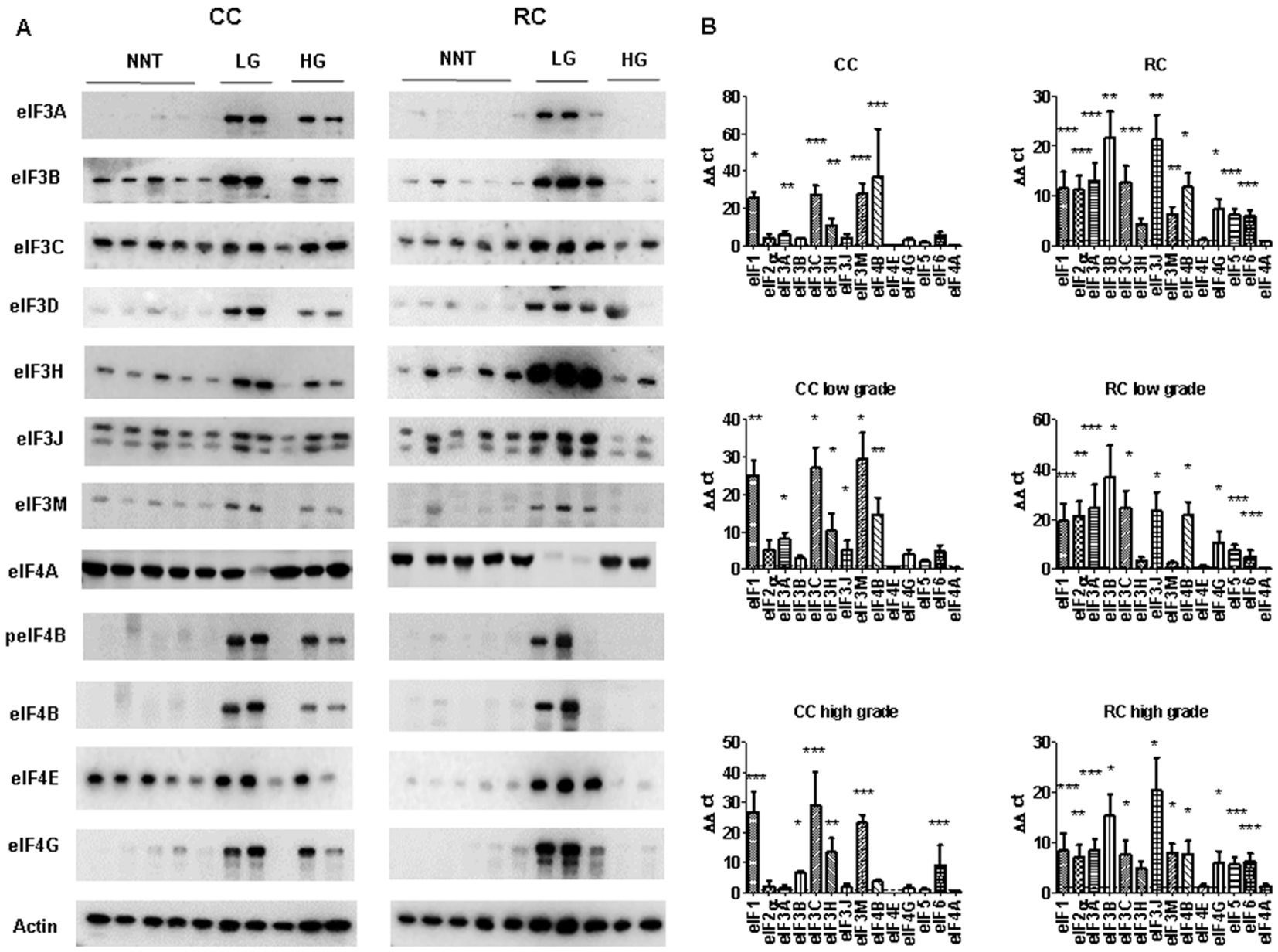

Figure 3: eIF expression levels in low and high grade CC and RC. (A) Graph shows Western blot analysis of low grade (LG) and high grade (HG) CC and RC compared to non- NNT. Equal amounts of protein have been resolved on SDS PAGE and immunoblotted with various eIF subunits and $\beta$-actin (loading control) antibodies. (B) qRT-PCR of various eIF subunits from LG and HG CC and RC compared NNT. Three independent experiments were carried out. Bars represent mean \pm SEM. ${ }^{*} \mathrm{p}<0.05,{ }^{* *} \mathrm{p}<0.01,{ }^{* * *} \mathrm{p}<0.001$. Statistical analysis: 2-way ANOVA with Bonferroni posttest. 
In order to investigate the effect of silencing of eIF1, eIF5 and eIF6, HCT116 cells were transfected with corresponding siRNA constructs and the knockdown effect was assessed for three time points. A knockdown effect at protein level close to $90 \%$ was achieved for eIF1 (Figure 5A), eIF5 (Figure 6A) and eIF6 (Figure 7A) at all three time points. The transfection strongly reduced the proliferation of HCT116 cells which expressed eIF1, eIF5 and eIF6 specific siRNAs, but had no effect on MOCK control.

Upon transfecting HCT116 cells for $24 \mathrm{~h}, 48 \mathrm{~h}$ and $72 \mathrm{~h}$ with the respective siRNAs, mRNA expression of
eIF1 (Figure 5B), eIF5 (Figure 6B) and eIF6 (Figure $7 \mathrm{~B})$ was reduced for all three initiation factors compared to cells transfected with scrambled RNA. The effect of eIF1, eIF5 and eIF6 gene knockdown on apoptosis was analyzed by YO-PRO ${ }^{\circledR}-1$ staining. The apoptosis rate of cells transfected with eIF1 (Figure 5D), eIF5 (Figure 6D) and eIF6 siRNAknockdown constructs (Figure 7D) was significantly decreased compared to negative control cells $72 \mathrm{~h}$ after transfection.

Silencing of eIF1 (Figure 5C), eIF5 (Figure 6C) and eIF6 (Figure 7C) led to a significant reduction of cell viability at all 3 time points $(24 \mathrm{~h}, 48 \mathrm{~h}, 72 \mathrm{~h})$.
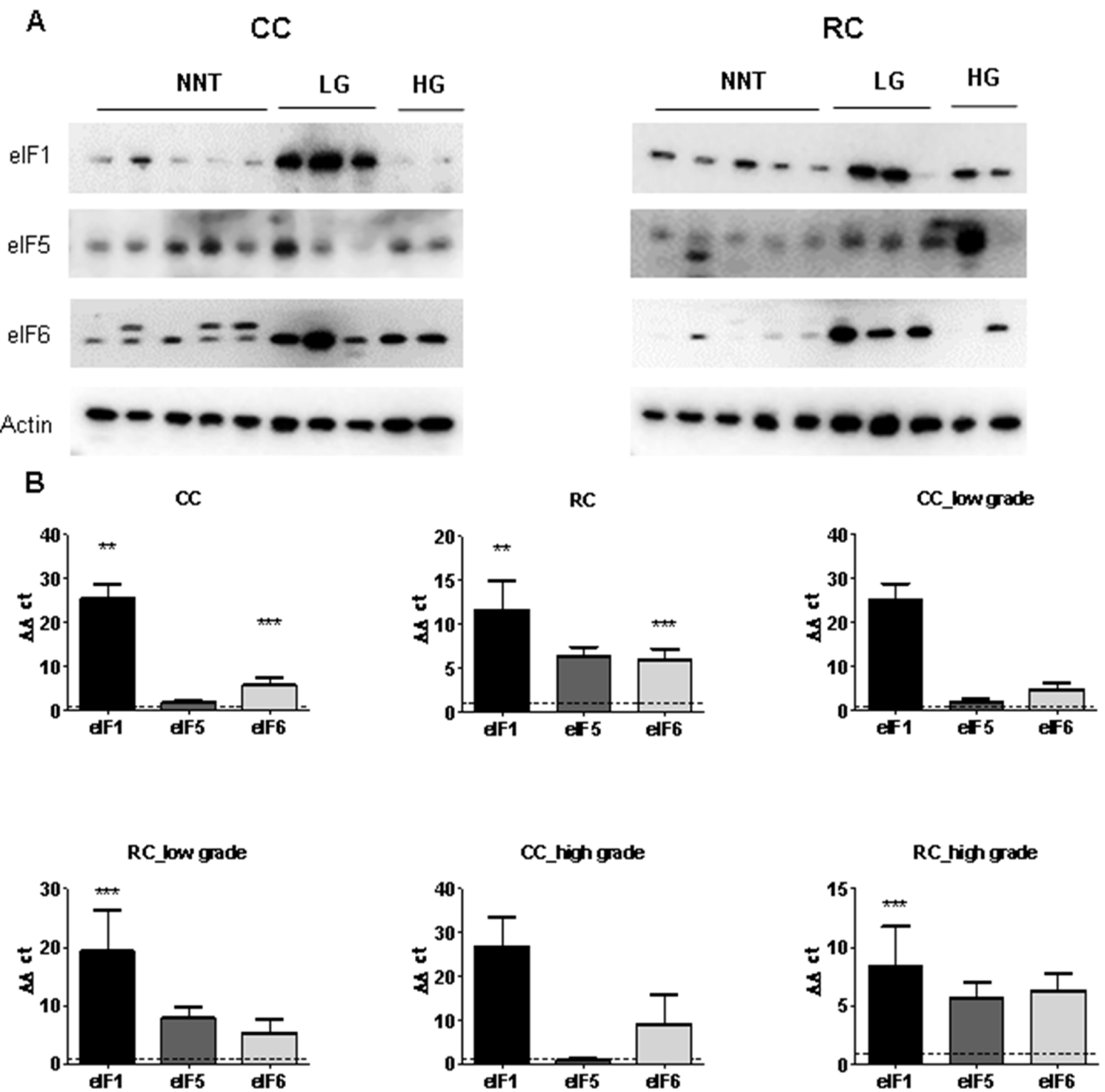

Figure 4: eIF1, eIF5 and eIF6 expression levels in low and high grade CC and RC. (A) Western blot of eIF1, eIF5 and eIF6 from LG and HG CC and RC NNT. Equal amounts of protein from each pair were resolved on SDS PAGE and immunoblotted with antibodies directed against eIF1, eIF5, eIF6 and $\beta$-actin (loading control). (B) qRT-PCR of eIF1, eIF5 and eIF6 from LG and HG CC and $\mathrm{RC}$ compared to NNT. Three independent experiments were carried out. Bars represent mean \pm SEM. ${ }^{* * *} \mathrm{p}<0.01,{ }^{* * *} \mathrm{p}<0.001$. Statistical analysis: 2-way ANOVA with Bonferroni posttest. 
In addition, we evaluated the consequences of siRNA-mediated eIF1, eIF5 and eIF6 depletion in HT29 cells. The knockdown effect was assessed at three time points $(24 \mathrm{~h}, 48 \mathrm{~h}$ and $72 \mathrm{~h}$ ). A knockdown effect at protein level close to $60 \%$ was achieved for eIF1 (Supplementary Figure 13A), eIF5 (Supplementary Figure 14A) and eIF6 (Supplementary Figure 15A) at all three time points.

The mRNA expression of eIF1 (Supplementary Figure 13B), eIF5 (Supplementary Figure 14B) and eIF6 (Supplementary Figure 15B) was reduced for all three subunits compared to cells transfected with scrambled RNA. Silencing of eIF1 (Supplementary Figure 13C), eIF5 (Supplementary Figure 14C) and eIF6 (Supplementary Figure $15 \mathrm{C}$ ) led to a lower reduction of cell viability at all 3 time points $(24 \mathrm{~h}, 48 \mathrm{~h}, 72 \mathrm{~h})$ in HT29 cells in comparison to HCT116 knockdown. The apoptosis rate of cells transfected with eIF1 (Supplementary Figure 13D), eIF5 (Supplementary Figure 14D) and eIF6 siRNAknockdown constructs (Supplementary Figure 15D) displayed lower decrease only at the $72 \mathrm{~h}$ time point.
Clonogenicity was evaluated by Giemsa staining. Colony formation was reduced 14 days after seeding in all transfected cells (Supplementary Figure 16A 16C). The effect of eIF1, eIF5A and eIF6 knockdown on $\mathrm{CRC}$ cell motility was investigated by assessing the transmigration competence of cells through filters coated with an extracellular matrix. The cells exhibited a reduced capability to transmigrate upon eIF1, eIF5 and eIF6 (Supplementary Figure 18D - 18F) knockdown compared to control cells.

\section{Knockdown of eIF1, eIF5 and eIF6 leads to reduced translation}

The effects of eIF1, eIF5 and eIF6 knockdown on translation initiation were investigated by sucrose density gradient profiling. After sucrose density gradient centrifugation of cell lysates, polysomes, $80 \mathrm{~S}$ ribosomes and free $40 \mathrm{~S}$ and $60 \mathrm{~S}$ subunits were detected by monitoring their $\mathrm{A}_{254 \mathrm{~nm}}$ as described in the methods section.
A

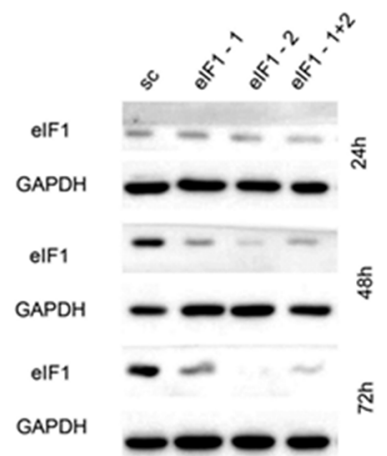

B
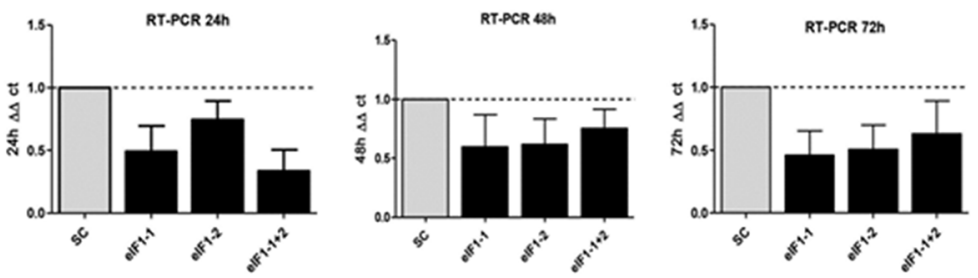

$\mathrm{C}$
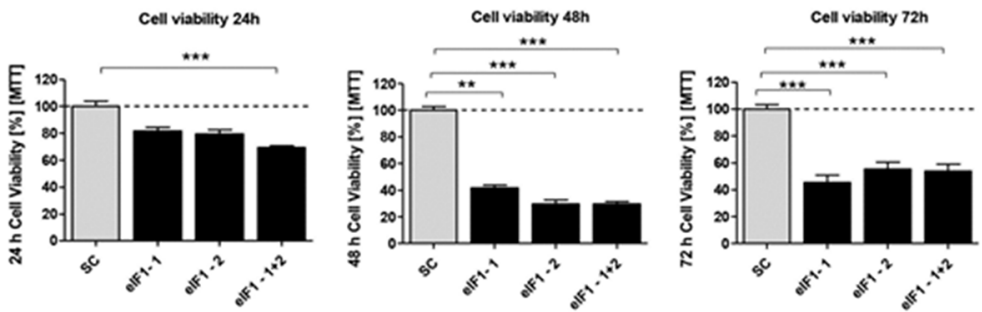

D

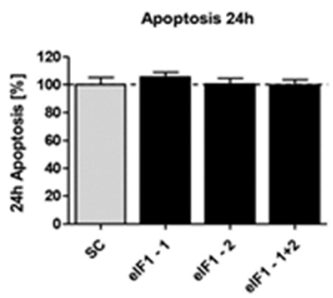

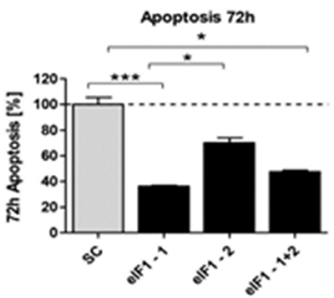

Figure 5: In vitro characterization of eIF1 knockdown effect in HCT116 cells. (A) Protein expression of eIF1-siRNA knockdown after 24h, 48h and 72h compared to SC control (B) mRNA expression level of eIF1 in HCT116 cells compared to the control group. (C) Cell viability in HCT116 cells transfected with eIF5 siRNA after 24h, 48h and 72h (D) Graphs show apoptosis rate after eIF1 knockdown compared to the SC after $24 \mathrm{~h}, 48 \mathrm{~h}$ and $72 \mathrm{~h}$. Three independent experiments were carried out. Bars represent mean \pm SEM. ${ }^{*} \mathrm{p}$ $<0.05,{ }^{* *} \mathrm{p}<0.01,{ }^{* * *} \mathrm{p}<0.001$. Statistical analysis: 2-way ANOVA with Bonferroni posttest. 
Non-transfected HCT116 cells showed some free $40 \mathrm{~S}$ and $60 \mathrm{~S}$ subunits, a large $80 \mathrm{~S}$ peak and low numbers of polysomes. After eIF1 knockdown, increased levels of free $60 \mathrm{~S}$ subunits and a marked decrease of the $80 \mathrm{~S}$ peak were observed suggesting a defect in translation initiation. Furthermore, fewer polysomes were recorded in the $e I F 1$ knockdown profile, indicating reduced translation rates (Supplementary Figure 17A). eIF5 knockdown also led to decreased levels of polysomes. In addition, the levels of free $40 \mathrm{~S}$ and $60 \mathrm{~S}$ ribosomal subunits relative to $80 \mathrm{~S}$ ribosomes were increased, suggesting less efficient translation initiation (Supplementary Figure 17B). Similarly, eIF6 knockdown resulted in a decrease in polysomes and an increase of the levels of free ribosomal subunits relative to 80 S ribosomes (Supplementary Figure 17C). Additionally, we evaluated the sedimentation of the 40S subunit protein RPS6 by Western Blotting. Compared to the MOCK profile, RPS6 levels were reduced in the polysome fractions of eIF1- eIF5- and eIF6 silenced cells. This is in line with the reduced polysome levels observed in the recorded profiles and further confirms that knockdown of all three initiation factors resulted in a reduction of polysomes consistent with reduced initiation of translation.

In conclusion, knockdown of all three initiation factors resulted in a reduction of polysomes consistent with reduced initiation of translation.

\section{Effect of eIF1, eIF5 and eIF6 knockdown on apoptosis and proliferation}

We evaluated the consequences of siRNA-mediated eIF1, eIF5 and eIF6 knockdown in HCT116 cells and HT29 cells, by measuring apoptosis and cell proliferation. We tested an alternative apoptotic response pathway by using western blotting and qRT-PCR to examine poly (ADPribose) polymerase (PARP) cleavage and cleaved caspase 3 . The control cells showed a decrease at the time point $24 \mathrm{~h}$ for all three siRNAs. Compared to control cells, eIF1, eIF5 and eIF6 knockdown resulted in increased PARP in HCT116 cells after $24 \mathrm{~h}$ (Supplementary Figure 18A - 18C). The time
A

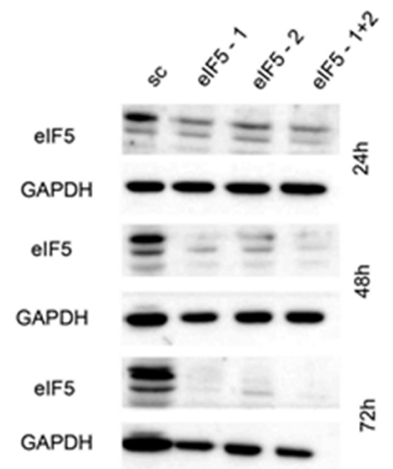

B
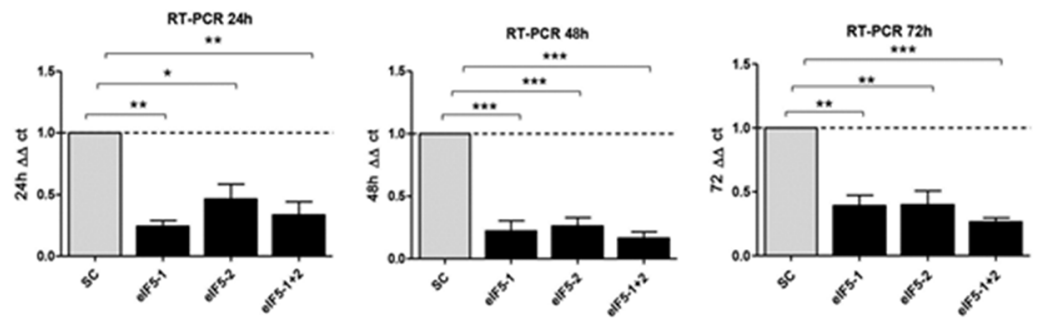

C
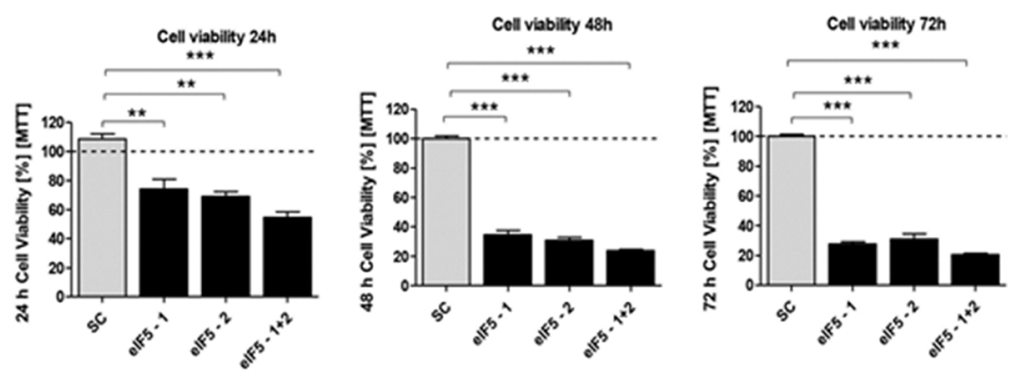

D

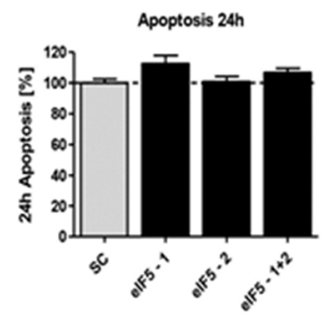

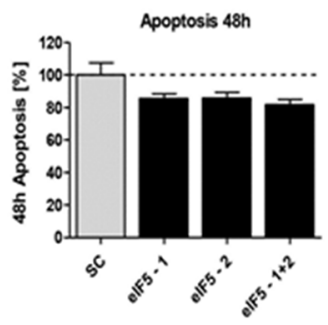

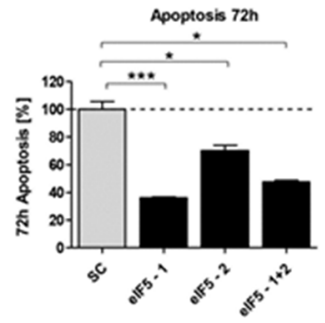

Figure 6: In vitro characterization of eIF5 knockdown effect in HCT116 cells. (A) Protein expression of eIF5-siRNA knockdown after 24h, 48h and 72h compared to SC. (B) mRNA expression level of eIF5 in HCT116 cells compared to SC. (C) Cell viability in HCT116 cells transfected with eIF5 siRNA after 24h, 48h and 72h. (D) Graphs show apoptosis rate after eIF5-siRNA knockdown compared to the $\mathrm{SC}$ after $24 \mathrm{~h}, 48 \mathrm{~h}$ and $72 \mathrm{~h}$. Three independent experiments were carried out. Bars represent mean $\pm \mathrm{SEM} .{ }^{*} \mathrm{p}<0.05,{ }^{* *} \mathrm{p}<0.01,{ }^{* * *} \mathrm{p}<0.001$. Statistical analysis: 2-way ANOVA with Bonferroni posttest. 
points $48 \mathrm{~h}$ and $72 \mathrm{~h}$ displayed a decreased PARP in HCT116 cells for eIF1, eIF5 and eIF6 knockdown compared to the control cells (Supplementary Figure 18A - 18C). We next investigated the effect of eIF1, eIF5 and eIF6 depletion in HT29 cells. Compared to control cells, eIF1, eIF5 and eIF6 knockdown resulted in a less decreased PARP expression in HT29 cells for all three time points (Supplementary Figure $18 \mathrm{D}-18 \mathrm{~F})$. We evaluated the consequences of siRNAmediated eIF1, eIF5 and eIF6 knockdown in HCT116 cells on mRNA level (Supplementary Figure 19A - 19C). These results were also evaluated on mRNA level for the HT29 cells (Supplementary Figure 20A - 20C).

Compared to control cells after $24 \mathrm{~h}$, eIF1, eIF5 and eIF6 knockdown resulted in increased cleaved caspase 3 activity in HCT116 cells (Supplementary Figure 18A 18C). The time points $48 \mathrm{~h}$ and $72 \mathrm{~h}$ displayed a decreased cleaved caspase 3 in HCT116 cells for eIF1, eIF5 and eIF6 knockdown compared to the control cells (Supplementary Figure 18A - 18C). These results were also evaluated on mRNA level (Supplementary Figure 21A - 21C).
The control cells and 24h eIF1, eIF5 and eIF6 knockdown constructs resulted in similar expression for cleaved caspase 3 in HT29 cells (Supplementary Figure 18D - 18F). After 48h eIF1, eIF5 and eIF6 knockdown resulted in decreased Cleaved Caspase 3 in HT29 cells compared to control cells (Supplementary Figure $18 \mathrm{D}-18 \mathrm{~F})$. After $72 \mathrm{~h}$, eIF1 knockdown resulted in similar expression for Cleaved Caspase 3 in HT29 cells compared to control cells (Supplementary Figure 18D). The eIF5 knockdown resulted in decreased cleaved caspase 3 in HT29 cells compared to control cells after 72h (Supplementary Figure 18E). For eIF6, just eIF6-1+2 resulted in decreased cleaved caspase 3 in HT29 cells compared to control cells after $72 \mathrm{~h}$ (Supplementary Figure $18 \mathrm{~F})$. These results were also evaluated on mRNA level (Supplementary Figure 22A - 22C).

We next investigated the effect of eIF1, eIF5 and eIF6 knockdown on cell proliferation by using western blotting and qRT-PCR to examine Ki67 as proliferation marker. Compared to control cells after $24 \mathrm{~h}$ eIF1, eIF5 and
A

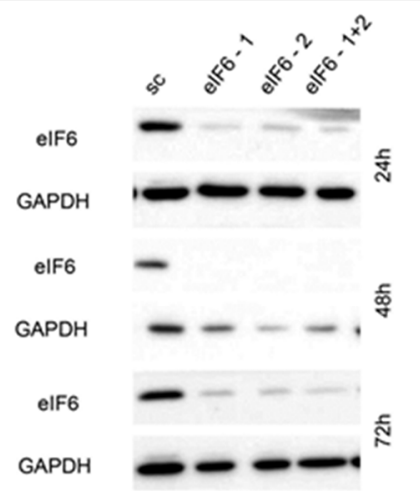

B

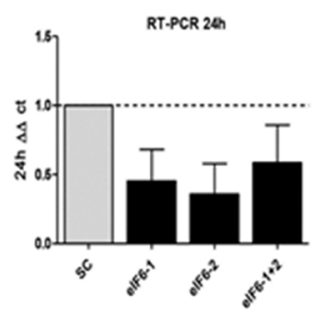

C

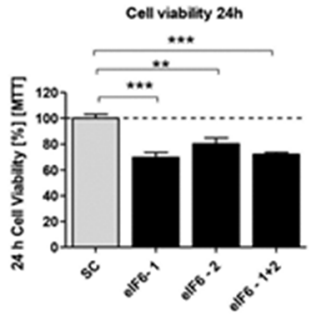

D

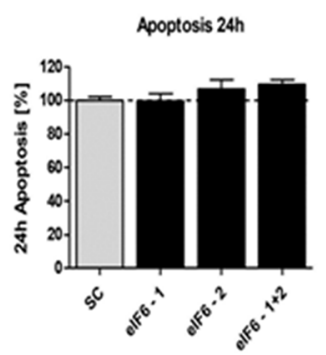

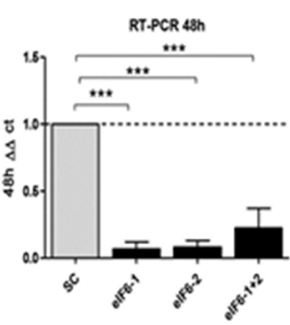
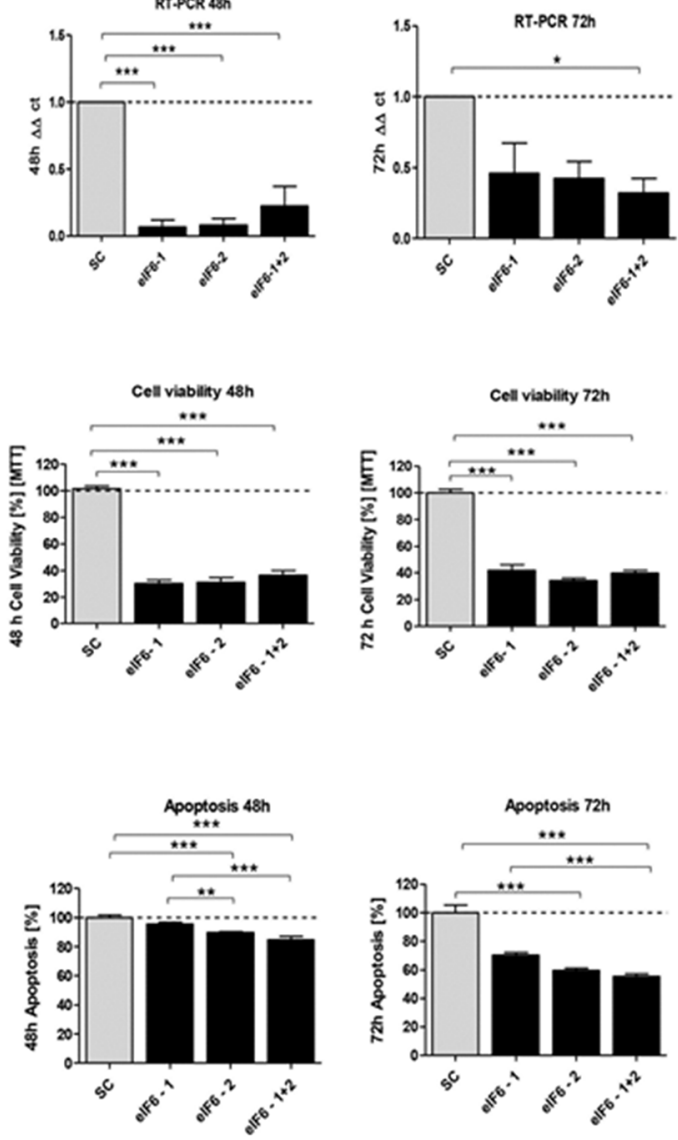

Figure 7: In vitro characterization of eIF6 knockdown effect in HCT116 cells. (A) Protein expression of eIF6-siRNA knockdown after 24h, 48h and 72h compared to SC control. (B) mRNA expression level of eIF6 in HCT116 cells compared to SC. (C) Cell viability in HCT116 cells transfected with eIF5 siRNA after 24h, 48h and 72h. (D) Graphs show apoptosis rate after eIF6 knockdown compared to the SC after $24 \mathrm{~h}, 48 \mathrm{~h}$ and $72 \mathrm{~h}$. Three independent experiments were carried out. Bars represent mean \pm SEM. ${ }^{*} \mathrm{p}<0.05,{ }^{* *} \mathrm{p}<$ $0.01,{ }^{* * *} \mathrm{p}<0.001$. Statistical analysis: 2-way ANOVA with Bonferroni posttest. 
eIF6 knockdown resulted in increased Ki67 in HCT116 cells. For the time points $48 \mathrm{~h}$ and $72 \mathrm{~h}$ we observed an increase in control cells compared to cells upon eIF1, eIF5 and eIF6 knockdown (Supplementary Figure 23A - 23C). Compared to control cells after 24h eIF1, eIF5 and eIF6 knockdown resulted in decreased Ki67 in HT29 cells (Supplementary Figure 23D - 23F). After 48h and $72 \mathrm{~h}$, eIF1 knockdown resulted in increased $\mathrm{Ki} 67$ in HT 29 cells compared to control cells (Supplementary Figure 23D). eIF5 and eIF6 knockdown did not result in changes compared to control cells for Ki67 in HT29 cells (Supplementary Figure 23E and Supplementary Figure $23 \mathrm{~F})$. These results were also evaluated on mRNA level for HCT116 cells (Supplementary Figure 24A - 24C) and HT29 cells (Supplementary Figure 25A - 25C).

\section{In situ detection of different eIFs by padlock probe approach}

In order to localize and analyze the distribution of eIF1, eIF5 and eIF6 transcripts in CC and RC vs. NNT, we performed an mRNA-based in situ detection approach (Supplementary Figure 26 and Supplementary Figure 27). In situ detection allows for visualization of single mRNA transcripts (Supplementary Figure 26 and Supplementary
Figure 27). In situ detection confirmed an overexpression at the mRNA level of $e I F 1$ and $e I F 5$ in colon carcinoma vs. NNT $(\mathrm{p}<0.001$ and $\mathrm{p}<0.05)$ (Supplementary Figure 27A). In RC tissue, eIF5 was overexpressed compared to NNT $(\mathrm{p}<0.05)$ (Supplementary Figure 27B).

\section{PI3K/AKT/mTOR pathway member expression in CRC}

We investigated the expression patterns of mTORC1 and mTORC2 members in CRC patient samples, because this pathway is preceded by eIFs.

Immunoblot analyses of pRictor, Rictor, pAMPK, AMPK, pRaptor, Raptor, pmTOR, mTOR, pAKT, AKT, pPTEN, PTEN, pp70S6K, p70S6K, pRPS6, RPS6 and p4E-BP1, 4E-BP1 revealed a significantly higher expression of these proteins in CRC compared to the corresponding NNT (Figure 8A and Supplementary Figure 28). Increased mRNA expression levels of $m T O R$ and PTEN were observed in CRC (Figure 8B). When we separated the samples into groups of $\mathrm{CC}$ and $\mathrm{RC}$, however we observed that the overexpression of pmTOR, mTOR, pAKT, AKT, pp70S6K, p70S6K, p4E-BP1 and 4E-BP1 is restricted to the $\mathrm{RC}$ patients. The $\mathrm{CC}$ patient showed no significant change in the mTOR pathway expression at the
A

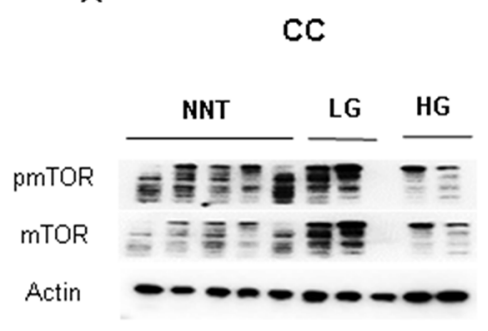

$\mathrm{CC}$

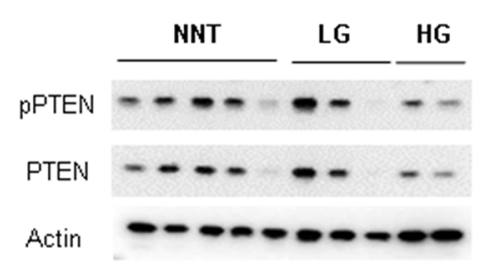

$\mathrm{RC}$

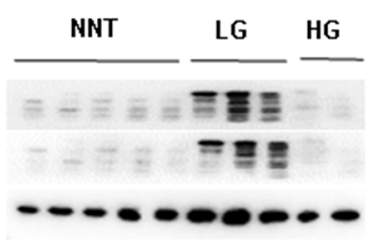

$\mathrm{RC}$

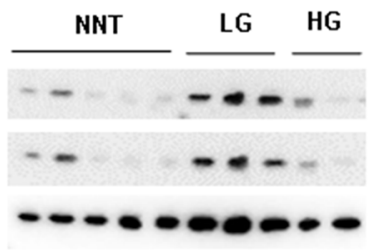

B
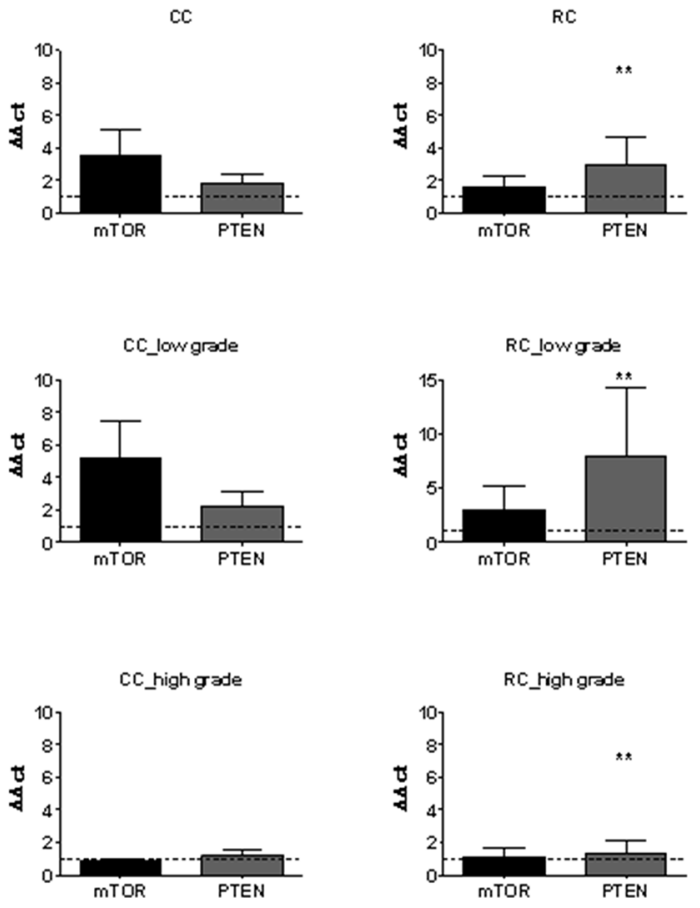

Figure 8: mTOR and PTEN expression in low and high grade CC and RC. (A) Graph shows Western blot analysis of LG and HG CC and RC compared to NNT. Equal amounts of protein were resolved on SDS PAGE and immunoblotted with antibodies directed against pmTOR, mTOR, pPTEN, PTEN and $\beta$-actin (loading control) antibodies. (B) qRT-PCR analyses of mTOR and PTEN LG and HG $\mathrm{CC}$ and RC compared to NNT. Three independent experiments were carried out. Bars represent mean $\pm \mathrm{SEM} .{ }^{*} \mathrm{p}<0.05,{ }^{* *} \mathrm{p}<0.01,{ }^{* * *} \mathrm{p}<$ 0.001. Statistical analysis: 2-way ANOVA with Bonferroni posttest. 
protein level (Figure 8A and Supplementary Figure 28). Despite the differences in protein expression, increased mRNA expression levels of $m$ TOR and PTEN (Figure 8B) were observed in both, $\mathrm{CC}$ and $\mathrm{RC}$.

Finally, we investigated the influence of tumor grade and compared the protein expression levels after separation into low and high grade CC and RC. Protein expression levels of mTOR, pAKT, AKT, pPTEN, PTEN, pp70S6K, p70S6K, p4E-BP1 and 4E-BP1 were significantly increased in low grade $\mathrm{RC}$ compared to low and high grade CC (Figure 8A and Supplementary Figure 28). In comparison, pmTOR, mTOR, pAKT, AKT, pPTEN, PTEN, pp70S6K, p70S6K, p4E-BP1 and 4E-BP1 were increased in high grade $\mathrm{RC}$ at protein level (Figure $8 \mathrm{~A}$ and Supplementary Figure 28). Increased mRNA expression levels of $m T O R$ and PTEN (Figure 8B) were observed in low grade $\mathrm{CC}$ and $\mathrm{RC}$, while there was no difference in the mRNA levels of $m T O R$ and PTEN in high grade CC and RC compared to NNCRM (Figure 8B, Supplementary Table 4 and Supplementary Table 5).

The targets, mTORC1 and mTORC2, pRictor, Rictor, pAMPK, AMPK, pRaptor, Raptor, pRPS6 and RPS6 showed a decreased activation in low grade $\mathrm{CC}$ and $\mathrm{RC}$ and an increase in protein activation in high grade $\mathrm{CC}$ and RC (Supplementary Figure 28). We also analyzed the phosphorylation levels of pRictor, Rictor, pAMPK, AMPK, pRaptor, Raptor, pmTOR, mTOR, pAKT, AKT, pp70S6K, p70S6K, pRPS6, RPS6, p4E-BP1 and 4E-BP1 to assess the activity of mTORC1/C2 (Supplementary Figure 29A and 29B). The phosphorylation levels of pRictor/Rictor and pAKT/AKT resulted in an increased activity in high grade $\mathrm{CC}$ and $\mathrm{RC}$. For low grade $\mathrm{RC}$, the phosphorylation levels of pAMPK/AMPK, pRaptor/ Raptor, pmTOR/mTOR, p4E-BP1/4E-BP1, pp70S6K/ p70S6K and pRPS6/RPS6 resulted in increased activity in low grade tumors (Supplementary Figure 29B).

A
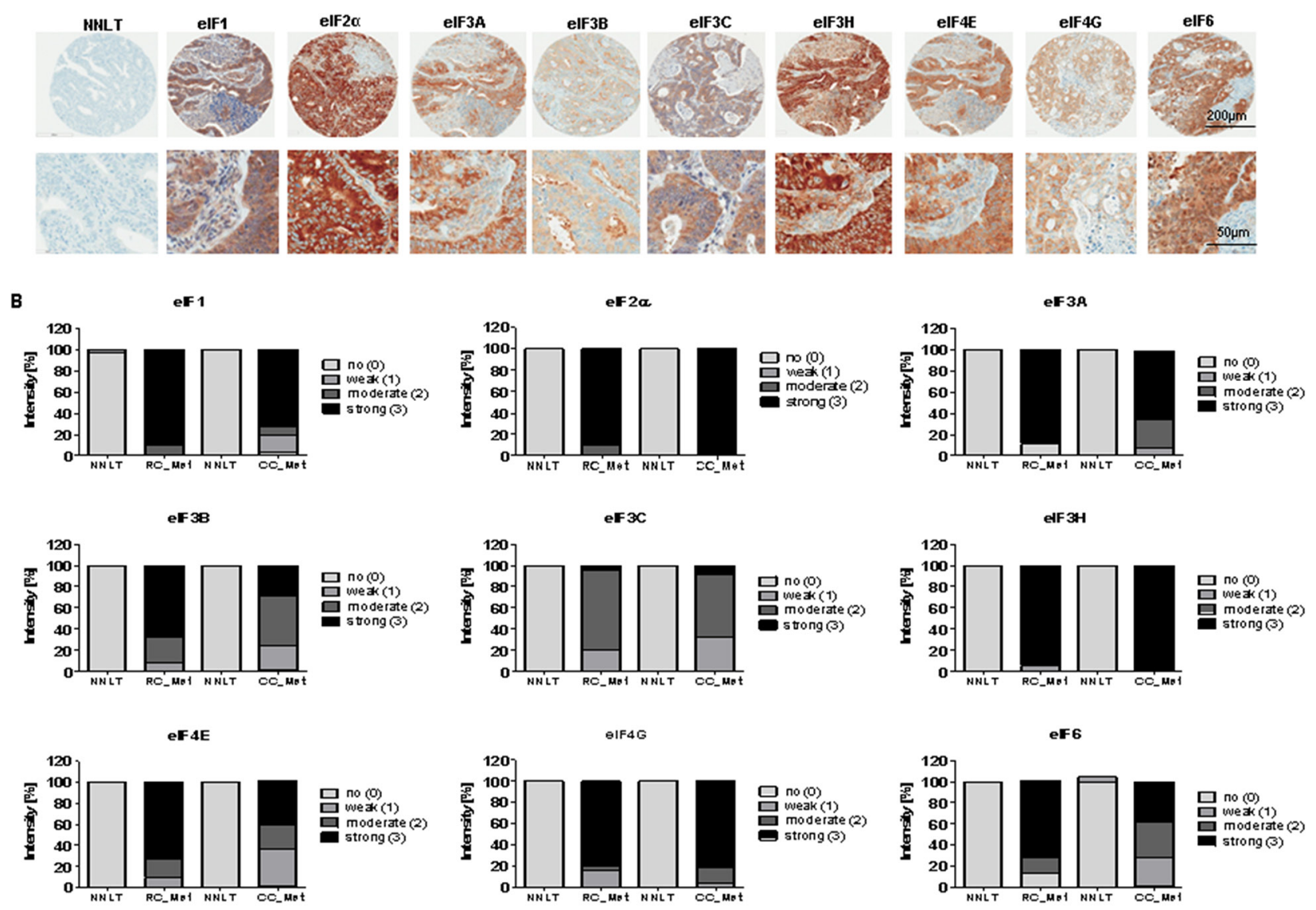

Figure 9: eIF expression in liver metastases of CC and RC compared to NNLT. (A) Representative pictures of immunohistochemical stainings from liver metasteses of primary CRC. Scale bars: $200 \mu \mathrm{m}$ and $50 \mu \mathrm{m}$. (B) Densitometric analyses of immunohistochemical stainings from various eIF subunits in liver metasteses of primary CC (CC- Met) and RC (RC-Met) compared to non-neoplastic liver tissues (NNLT). 


\section{PI3K/AKT/mTOR members and eIF expression in liver metastasis of primary colon and rectum carcinoma}

As CRC tumors predominantly metastasize in the liver, expression profiles of mTOR members and eIFs in CC and RC metastases were analyzed by IHC, immunoblot and qRT-PCR compared to matched nonneoplastic liver tissue (NNLT).

The IHC staining pattern of eIF subunits was found to be mainly cytoplasmic (Figure 9A). The subunits eIF $1,2 \alpha, 3 \mathrm{H}$ and $4 \mathrm{G}$ exhibited a stronger staining in the metastatic tissues compared to NNLT (Figure 9B). The staining intensities for eIF3A, eIF3B, eIF4E and eIF6 were increased compared to NNLT, but not as much as for the eIF subunits 1, 2 $\alpha, 3 \mathrm{H}, 4 \mathrm{G}$ (Figure 9B). eIF3C staining was only weak to moderate in the metastases (Figure 9B). IHC staining intensity of the subunits eIF $1,2 \alpha, 3 \mathrm{~A}, 3 \mathrm{~B}$, $3 \mathrm{H}, 4 \mathrm{E}, 4 \mathrm{G}$ and 6 was stronger in the $\mathrm{RC}$ metastases (RCMet) and no staining was found in the NNLT (Figure 9B). Only for eIF3C was weak to moderate staining found in RC-Met (Figure 9B). For eIF5, we observed no changes in the staining intensity in metastasis samples compared to the NNLT. The IHC data displayed a stronger eIF expression in $\mathrm{RC}$ Met samples compared to CC-Met.

Regarding the PI3K/AKT/mTOR pathway in the metastases, we found no changes in the expression of pmTOR, mTOR, pAKT, AKT, pPTEN, PTEN, pp70S6K and 4E-BP1 at the protein level (Supplementary Figure 30A and 30B) in CC-Mets and RC-Mets. On mRNA level, $m T O R$ and PTEN were significantly upregulated in CC- and RC-Met compared to NNLT (Supplementary Figure 30C).

Immunoblot analyses revealed peIF $2 \alpha$, eIF3B and eIF4E protein expression to be higher in metastatic CC and RC compared to NNLT (Supplementary Figure 30B). For eIF3K we only observed higher expression in RCMet but no changes in CC-Met (Supplementary Figure 30B). To evaluate the gene expression at mRNA level, we performed qRT-PCR and measured the transcripts of 13 eIF subunits by relative quantification normalized to $\beta$-actin. At the mRNA level, the eIF subunits $1,2 \alpha, 3 A$, $3 B, 3 C, 3 H, 3 M, 4 B, 4 E, 4 G, 5$ and 6 showed a significant overexpression in CC- and RC-Met compared to NNLT (Supplementary Figure 30D).

We next investigated the effect on protein expression of primary $\mathrm{CC}$ and $\mathrm{RC}$ tumors compared to the respective liver metastasis for mTOR pathway members and eIF subunits. From the mTOR members only pmTOR resulted in increased protein level compared to low and high grade primary CC and RC (Supplementary Figure 31A and Supplementary Figure 31B). Next, we investigated the effect of eIFs on protein level in primary $\mathrm{CC}$ and $\mathrm{RC}$ compared to the respective liver metastasis. peIF $2 \alpha$ and eIF3B displayed an increased protein level in liver metastases compared to low and high grade primary CC and RC (Supplementary Figure 32). We then evaluated the effect on protein expression in primary low and high grade RC compared to liver metastases, eIF3B and eIF3K resulted in an increase (Supplementary Figure 33).

\section{DISCUSSION}

Recent studies on mRNA transcription and protein synthesis in cancer have demonstrated a key role for translational control in tumorigenesis [10]. Activation of mTOR signaling has been shown to be a hallmark of cancer and has been linked to cell growth and cell cycle progression [22-24].

In our study, we investigated the expression patterns of mTOR pathway components in CRC patients. We also separated the CRC patients into $\mathrm{CC}$ and $\mathrm{RC}$ and noticed remarkable differences in the expression patterns between these two groups. The final step was to sub-classify CC and $\mathrm{RC}$ patient samples into low and high grade tumors. mTOR and its upstream target AKT as well as the downstream targets p70S6K and 4E-BP1 displayed an overexpression only in RC, but not in CC. The tendency was the same in low and high grade RC tumors. Upstream and downstream targets of mTOR seem to be involved in cancer progression in low and high grade $\mathrm{RC}$ while in low grade and high grade $\mathrm{CC}$ the mTOR pathway members plays a less important role.

Previously, other groups found a significant increase of eIF3 subunits in CRC [25]. We also found that eIF3 subunits were differentially expressed at the protein and mRNA level in CC and RC. It is known from the literature, that eIF3A, eIF3B and eIF3M overexpression has been detected in the CC cell lines SW1116 [25-27]. eIF3C was found to be an oncogene and was shown to be increased in cancer cells [28], which is confirmed by our findings in CRC. eIF3H has been associated with CRC risk and was therefore suggested to act as CRC susceptibility gene [29]. We confirmed the CRC data from the literature and report differences in the expression pattern of eIF3 subunits in low and high grade CC and RC.

Previous studies have shown an overexpression of eIF4G and eIF4E in different cell lines, including CRC cell lines, and they have also been linked to carcinogenesis $[30,31]$. This supports the results presented here showing that eIF4B displayed an overexpression in $\mathrm{CRC}$ and eIF4G is involved in RC formation. eIF1, eIF2, eIF3 and eIF5 have been reported as essential for translation initiation [32]. Previously, transient eIF2 $\alpha$ expression was described as increased in normal cells, whereas constitutive overexpression supported tumor initiation and progression [1]. Knockdown of eIF3D in HCT116 cells attenuated proliferation and increased stress-driven apoptosis [4].

eIF4E is one of the most thoroughly investigated translation factors involved in cancer biology, especially in CRC. Together with eIF4A and eIF4G it forms the trimetric eIF4F complex [33]. eIF4E plays a major role in the regulation of tumor growth, invasion and metastasis $[31,34]$. Compared to previous studies, we also showed 
Table 1: Clinical and pathological characteristics of 40 patients with colorectal carcinoma. For each biochemically assessed CC and RC patient, numbered from 1 to 40, the clinical and pathological characteristics, including sex, age, TNM, stage, histological type and the presence of positive lymph nodes are listed

\begin{tabular}{|c|c|c|c|c|c|c|}
\hline Patient & Gender & Age & Localization & TNM & Stage & Histological type \\
\hline 1 & M & 66 & Colon & pT1 N0 M0 & I & $\begin{array}{l}\text { well differentiated } \\
\text { adenocarcinoma }\end{array}$ \\
\hline 2 & W & 62 & Transverse Colon & pT2 pN0 & I & $\begin{array}{c}\text { well differentiated mucinous } \\
\text { adenocarcinoma }\end{array}$ \\
\hline 3 & W & 65 & Colon & pT3b pN0 & IIA & $\begin{array}{l}\text { moderatly differentiated } \\
\text { mucinous adenocarcinoma }\end{array}$ \\
\hline 4 & W & 77 & Ascending Colon & pT3b pN0 & IIA & $\begin{array}{l}\text { moderatly differentiated } \\
\text { mucinous adenocarcinoma }\end{array}$ \\
\hline 5 & W & 89 & Sigmoid Colon & pT3b pN0 & IIA & $\begin{array}{l}\text { moderatly differentiated } \\
\text { adenocarcinoma }\end{array}$ \\
\hline 6 & M & 58 & Sigmoid Colon & pT3a pN0 & IIA & $\begin{array}{l}\text { moderatly differentiated } \\
\text { invasive adenocarcinoma }\end{array}$ \\
\hline 7 & M & 74 & Ascending Colon & pT3 pN0 & IIA & $\begin{array}{l}\text { moderatly differentiated } \\
\text { adenocarcinoma }\end{array}$ \\
\hline 8 & M & 76 & Sigmoid Colon & pT3b pN0 & IIA & $\begin{array}{l}\text { moderatly differentiated } \\
\text { adenocarcinoma }\end{array}$ \\
\hline 9 & M & 65 & Transverse Colon & pT3a pN0 & IIA & $\begin{array}{l}\text { moderatly differentiated } \\
\text { adenocarcinoma }\end{array}$ \\
\hline 10 & M & 79 & Sigmoid Colon & pT3a pN0 & IIA & $\begin{array}{l}\text { moderatly differentiated } \\
\text { adenocarcinoma }\end{array}$ \\
\hline 11 & M & 48 & Sigmoid Colon & pT4a N0 & IIB & $\begin{array}{l}\text { well differentiated } \\
\text { adenocarcinoma }\end{array}$ \\
\hline 12 & W & 75 & Cecum & pT2 pN1a & IIIA & $\begin{array}{l}\text { moderatly differentiated } \\
\text { adenocarcinoma }\end{array}$ \\
\hline 13 & M & 71 & Sigmoid Colon & pT4a N2a M0 & IIIC & $\begin{array}{l}\text { moderatly differentiated } \\
\text { adenocarcinoma }\end{array}$ \\
\hline 14 & M & 82 & Sigmoid Colon & $\begin{array}{l}\text { pT4a L1 V1 } \\
\text { N2b }\end{array}$ & IV & $\begin{array}{l}\text { low differentiated } \\
\text { adenocarcinoma }\end{array}$ \\
\hline 15 & M & 78 & Sigmoid Colon & pT3 N2a M1a & IVA & $\begin{array}{l}\text { moderatly differentiated } \\
\text { adenocarcinoma }\end{array}$ \\
\hline 16 & W & 52 & Sigmoid Colon & pT4a pN2a V1 & IVA & $\begin{array}{c}\text { moderatly differentiated } \\
\text { adenocarcinoma }\end{array}$ \\
\hline 17 & M & 74 & Sigmoid Colon & pT3 N1a M1a & IVA & $\begin{array}{l}\text { moderatly differentiated } \\
\text { adenocarcinoma }\end{array}$ \\
\hline 18 & M & 71 & Rectum & pT2 N0 M0 & I & $\begin{array}{l}\text { moderatly differentiated } \\
\text { adenocarcinoma }\end{array}$ \\
\hline 19 & W & 58 & Rectum & pT2 N0 M0 & I & $\begin{array}{l}\text { moderatly differentiated } \\
\text { adenocarcinoma }\end{array}$ \\
\hline 20 & W & 83 & Rectum & pT2 pN0 & I & $\begin{array}{l}\text { moderatly differentiated } \\
\text { adenocarcinoma }\end{array}$ \\
\hline 21 & M & 61 & Rectum & pT2 N0 M0 & I & $\begin{array}{c}\text { moderatly differentiated } \\
\text { adenocarcinoma }\end{array}$ \\
\hline
\end{tabular}

(Continued) 


\begin{tabular}{|c|c|c|c|c|c|c|}
\hline Patient & Gender & Age & Localization & TNM & Stage & Histological type \\
\hline 22 & $\mathrm{~W}$ & 64 & Rectum & pT3a pN0 & IIA & $\begin{array}{l}\text { moderatly differentiated } \\
\text { adenocarcinoma }\end{array}$ \\
\hline 23 & M & 77 & Rectum & pT3b pN0 & IIA & $\begin{array}{l}\text { moderatly differentiated } \\
\text { adenocarcinoma }\end{array}$ \\
\hline 24 & M & 56 & Rectum & pT3 N0 M0 & IIA & $\begin{array}{l}\text { moderatly differentiated } \\
\text { adenocarcinoma }\end{array}$ \\
\hline 25 & $\mathrm{~W}$ & 76 & Rectum & pT3 N0 M0 & IIA & $\begin{array}{l}\text { moderatly differentiated } \\
\text { adenocarcinoma }\end{array}$ \\
\hline 26 & M & 78 & Rectum & pT3 N0 M0 & IIA & $\begin{array}{l}\text { moderatly differentiated } \\
\text { adenocarcinoma }\end{array}$ \\
\hline 27 & W & 51 & Rectum & pT3 N0 M0 & IIA & $\begin{array}{l}\text { moderatly differentiated } \\
\text { adenocarcinoma }\end{array}$ \\
\hline 28 & M & 67 & Rectum & pT3 N0 M0 & IIA & $\begin{array}{l}\text { moderatly differentiated } \\
\text { adenocarcinoma }\end{array}$ \\
\hline 29 & M & 77 & Rectum & pT3 N0 M0 & IIA & $\begin{array}{l}\text { moderatly differentiated } \\
\text { adenocarcinoma }\end{array}$ \\
\hline 30 & $\mathrm{~W}$ & 84 & Rectum & pT4a NB1b M0 & IIIA & $\begin{array}{l}\text { moderatly differentiated } \\
\text { adenocarcinoma }\end{array}$ \\
\hline 31 & M & 55 & Rectum & pT3 N2b & IIIB & $\begin{array}{l}\text { highly differentiated } \\
\text { adenocarcinoma }\end{array}$ \\
\hline 32 & M & 60 & Rectum & pT3 NB1b & IIIB & $\begin{array}{l}\text { highly differentiated } \\
\text { adenocarcinoma }\end{array}$ \\
\hline 33 & W & 62 & Rectum & pT3 N2a M0 & IIIB & $\begin{array}{l}\text { highly differentiated } \\
\text { adenocarcinoma }\end{array}$ \\
\hline 34 & W & 76 & Rectum & pT3 N1a M0 & IIIB & $\begin{array}{l}\text { highly differentiated } \\
\text { adenocarcinoma }\end{array}$ \\
\hline 35 & $\mathrm{~W}$ & 47 & Rectum & pT4a NB1b Mx & IIIC & $\begin{array}{l}\text { highly differentiated } \\
\text { adenocarcinoma }\end{array}$ \\
\hline 36 & M & 55 & Rectum & pT3 N2b & IIIC & $\begin{array}{l}\text { highly differentiated } \\
\text { adenocarcinoma }\end{array}$ \\
\hline 37 & M & 73 & Rectum & pT4b N1c M1a & IV & $\begin{array}{l}\text { highly differentiated } \\
\text { adenocarcinoma }\end{array}$ \\
\hline 38 & $\mathrm{~W}$ & 58 & Rectum & pT3 N2a M1b & IVB & $\begin{array}{l}\text { highly differentiated } \\
\text { adenocarcinoma }\end{array}$ \\
\hline 39 & $\mathrm{~W}$ & 58 & Rectum & pT3 N2a Mx & IVB & $\begin{array}{l}\text { highly differentiated } \\
\text { adenocarcinoma }\end{array}$ \\
\hline 40 & M & 62 & Rectum & pT3 N1a M0 & IIIB & $\begin{array}{l}\text { highly differentiated } \\
\text { adenocarcinoma }\end{array}$ \\
\hline
\end{tabular}

that eIF2 $\alpha$, eIF4B, eIF4E and eIF4G were significantly overexpressed at protein and mRNA level in CRC. This implies the influence of the eIF4F complex in protein translation in CRC.

eIF6 expression limits cell growth and transformation [35]. It is known that eIF6 is part of a multi-protein complex connected with the RNA-induced silencing complex (RISC), which is the major complex regulating miRNA activity. Previous studies have reported eIF6 overexpression in ovarian serous carcinoma, leukemia, head and neck carcinoma, as well as CRC [18, 35-37]. We also saw a significant increase of eIF6 but only in low and high grade $\mathrm{RC}$ at protein and mRNA level. This finding suggests that eIF6 may play a central role in the translation initiation in RC. 
eIF5 overexpression has been reported in different cancer types and is considered to be a predictive tumor marker [38]. eIF1 has been demonstrated to bind eIF5 and thereby potentially interferes with its GTPase activator protein function [39].

As the eIF 1, 5 and 6 turned out to be the novel promising candidates in targeting CRC we investigated them in more detail in knockdown experiments. After successful silencing of eIF1, eIF5 and eIF6, both the proliferation rate and the clonogenicity of HCT116 cells were significantly reduced. Apoptosis significantly increased later during treatment $(72 \mathrm{~h})$. The silencing of eIF 1, eIF5 and eIF6 resulted in a reduction of polysomes, indicating reduced overall translation.

\section{MATERIALS AND METHODS}

\section{Tissue microarrays (TMAs)}

Tumor material was obtained with informed consent from 40 CRC patients with clinical and pathological data (Table 1) at the Medical University of Graz and the St. John of God Hospital Graz under approval from the ethics committee of the Medical University of Graz and the ethics committee of the St. John of God Hospital Graz (23-015 ex 10/11).

Kaplan-Meier curves were generated using the survival $\mathrm{R}$ package. The log rank test was applied to test for association of survival and gene expression. A $p$ value $<0.05$ was considered as statistically significant. To identify the association between gene expressions, stratified by median, and survival, The Cancer Genome Atlas (TCGA) public dataset including 201 and 70 subjects suffering from colon adenocarcinoma and rectum carcinoma, respectively, was analyzed.

Tumor staging was reviewed by an experienced, board-certified pathologist (J. H.) using haematoxylin and eosin stained sections and relevant tumor areas were marked on the slide. Tissue cores of $1.2 \mathrm{~mm}$ in diameter were punched out from the chosen tumor area and embedded as an array in a fresh paraffin block. Tissue sections were cut at $4 \mu \mathrm{m}$ and mounted on adhesive-coated glass slides compatible for immunohistochemical staining and analysis.

Seventeen patient-derived tumors from liver metastases of primary $\mathrm{CC}$ and $\mathrm{RC}$ were used to generate liver metastasis TMA (LM TMA). It was generated from 11 CC-Met (27\% female; $73 \%$ male) and 6 RC-Met patients (100\% male) and non-neoplastic liver tissue (NNLT) with a total of 185 spots.

Twenty-one samples from primary CC (16 low grade and 5 high grade primary CCs), 24 samples from primary RC (14 low grade and 10 high grade primary RCs), 16 samples of LM from primary CC and RC patients (9 CCMet and 7 RC-Met), 19 samples of NNT (9 CC and 10 RC healthy tissues samples) and 14 NNLT (5 non-neoplastic liver tissue from $\mathrm{CC}$-Met and 4 non-neoplastic liver tissues from RC-Met samples) served as healthy controls for immunoblot and RT-PCR.

Tumor type and grade were histologically diagnosed according to the current WHO classification (Hamilton and Aaltonen, 2000), the tumor stage according to UICC.

\section{Immunohistochemistry (IHC)}

IHC was performed on a Ventana Immunostainer XT (Ventana Medical Systems, Tucson, USA), using an ultraVIEW universal DAB Detection Kit (Ventana Medical Systems, Tucson, USA) and cell conditioning solution for 30 minutes using heat induced epitope retrieval (HIER). The primary antibodies were incubated for 30 minutes using different dilutions (Supplementary Table 6).

Two independent observers (N. GS., J. H.), blinded to the clinical data relating to the respective cases, used light microscopy for scoring. eIF expression was evaluated with respect to staining intensity (intensity score $0-3 ; 0$ no staining, 1 weak, 2 moderate and 3 strong) and percentage of positive cells (proportion score; 0-100\%).

\section{In situ detection using padlock probes}

Tissues were deparaffinized, permeabilized with pepsin and subjected to in situ reactions. In situ detection of eIF1, eIF5 and eIF6 detected in situ using a multiplexed reaction.

All oligonucleotides were designed using CLC Main Workbench software (CLC Bio Workbench Version 7.6, Qiagen; Venlo, Netherlands). mRNA sequences were retrieved from the National Center for Biotechnology Information (NCBI) with the GenBank accession numbers NM_005801(eIF1), NM_001969 (eIF5) and NM_002212 (eIF6). The padlock probes were designed and ordered 5' phosphorylated (Integrated DNA Technologies; Coralville, IA, USA). The primers were purchased from IDT DNA, detection oligos (Biomers; Ulm, Germany). Primer-, padlock probe- and detection oligo- sequences are shown in Supplementary Table 1.

Imaging was performed using a Zeiss Observer. Z1 inverted microscope (Carl Zeiss; Oberkochen, Germany) with a 20x objective and the ZEN 2.3 software (Carl Zeiss, blue edition, Version 2.3.64.0). Z-Stacks were projected into one layer by a maximum intensity projection with ZEN 2012 black software (Carl Zeiss, Version 8.1). For a better visualization, the brightness and contrast of images were adjusted with ZEN 2012 black software (Carl Zeiss). CellProfiler software (Version 2.1.1) was used for the quantification of signals. The modification includes a background correction, removing fluorescent signals which were detectable in at least two fluorescent channels simultaneously as this indicates unspecificity. Statistical analyses were performed using the GraphPad Prism software, version 6.01 (GraphPad Prism, Inc., La Jolla, USA). An unpaired t-test was applied to compare cancer 
vs. NNT in every group (colon and rectum). Results were considered statistically significant when $\mathrm{p}<0.05$.

\section{Protein extraction and immunoblot}

All tumor tissue samples were acquired during surgery, immediately frozen in liquid nitrogen and stored at $-80^{\circ} \mathrm{C}$.

Frozen tissue samples were homogenized with a MagNA Lyser homogenizer (Roche Diagnostics, RischRotkreuz, Switzerland) and lysed in NP-40 Lysis buffer (0.05 M Tris- $\mathrm{HCl}, 5 \mathrm{mM} \mathrm{NaCl}, 0.5 \%$ NP-40, $0.1 \mathrm{mM}$ Pefabloc, 1 mM DTT, complete Mini, PhosSTOP). siRNA infected cells were scraped off into phosphate buffered saline (PBS) and lysed. The protein concentration was determined using Bradford protein assay (Biorad Protein Assay Dye Reagent, 500-0006; BioRad Laboratories $\mathrm{GmbH}$, Munich, Germany). Equal amounts of 30 $\mu \mathrm{g}$ protein were loaded onto SDS-PAGE gels $30 \%$ Acrylamid/ Bisacrylamid solution; ROTH, Karlsruhe, Germany), subjected to electrophoresis in Mini-vertical electrophoresis units (Hoefer Inc, Richmond, USA) and blotted onto PVDF membranes (Immobilin-P Transfer Membrane; Millipore, Massachusetts, USA) using a Semi Dry Blotting Unit (SCIE-PLAS; Cambridge, England). The membranes were blocked in TBS tween (TBST) with 5\% non-fat milk (AppliChem; Darmstadt, Germany) for $1 \mathrm{~h}$ at room temperature. The primary antibodies (Supplementary Table 7) were diluted in TBST, $5 \% \mathrm{BSA}$ and applied overnight at $4^{\circ} \mathrm{C}$. The membranes were washed with TBST, followed by incubation with a horseradish peroxidase conjugated secondary antibody (anti-mouse 1:3000 and anti-rabbit 1:5000; GE Healthcare Life Sciences, Buckinghamshire, England). Proteins were visualized using a chemiluminescence ECL kit (GE Healthcare Life Sciences), followed by exposure on the Image Quant LAS 500 (GE Healthcare, Little Chalfont, UK). The signal was normalized using anti- $\beta$-actin antibody (mAb dilution 1:2000, Sigma-Aldrich, Missouri, USA). Three independent experiments were carried out.

\section{Quantitative real-time PCR}

Total RNA was isolated from snap-frozen human primary CRC, metastases, NNT and NNLT using Trizol Reagent (Life Technologies; Woolston, UK), followed by extraction with phenol-chloroform. siRNA infected cells were washed three times with PBS, scraped off into PBS and lysed with Trizol Reagent. qRT-PCR was performed using the High-Capacity cDNA Reverse Transcription Kit (Applied Biosystems, FosterCity, USA) according to the manufacturer's instructions and the GeneAmp 9700 Thermocycler (Applied Biosystems; Foster City, USA). Primers and dilutions used to determine the expression of different eIFs are shown in Supplementary Table 8. For the qRT-PCR the Power SYBR Green PCR Master
Mix Kit (Applied Biosystems, Foster City, USA) was used in a 7900HT Fast Real-Time PCR System (Applied Biosystems, Foster City, USA). $\beta$-actin was used as housekeeping gene and the relative gene expression levels were calculated using the $2^{\Delta \triangle \mathrm{CT}}$ analysis method. Three independent experiments were carried out.

\section{Cell culture}

The HCT116 cell line was obtained from the American Type Culture Collection (ATCC) and maintained in McCoy 5A medium supplemented with $10 \%$ fetal bovine serum (FBS) and penicillin/ streptomycin $(100 \mu \mathrm{g} / \mathrm{ml})$, and incubated in a humidified atmosphere of $5 \% \mathrm{CO}_{2}$ at $37^{\circ} \mathrm{C}$. The HT29 cell line was kindly provided by $\mathrm{Cpo}-$ cellular phenomics \& oncology Berlin-Buch $\mathrm{GmbH}$ and maintained in DMEM medium supplemented with 10\% FBS and penicillin/ streptomycin $(100 \mu \mathrm{g} / \mathrm{ml})$, and incubated in a humidified atmosphere of $5 \% \mathrm{CO}_{2}$ at $37^{\circ} \mathrm{C}$.

\section{siRNA transfection}

We targeted the gene of interest by using small interfering RNAs (siRNAs) from QIAGEN (Hilden, Germany). For each gene of interest, two target sequences were used. For eIF1; 5'-GACCAGACATATCCTAG CTAA-3' and 5'-AAGCAATACCGTCATGTTTCA-3, for eIF5; 5'-AGGCGCTTAATCGGCCTCCAA-3' and 5'-CA GCCAGAAGTGCAACATGTA-3'; for eIF6; 5'-CTGCT TTGCCAAGCTCACCAA-3' and 5'-CTGGTGCATCC CAAGACTTCA-3'.

Transfection experiments were performed using Metafectene ${ }^{\mathrm{R}} \mathrm{Si}^{+}$transfection reagent (Biontex, Munich, Germany) according to the manufacturer's instructions. For the transfection, 1x SI buffer, Metafectene SI+ and siRNA were mixed into a drop. After an incubation of 15 $\mathrm{min}$ at room temperature $500 \mu \mathrm{l}$ cells (80 000 cells/ well) were seeded onto a 24 -well plate. Cells with transfection mix were cultured at $37^{\circ} \mathrm{C}$ in a humidified atmosphere of $5 \% \mathrm{CO}_{2}$. Cells were collected after incubation for $24 \mathrm{~h}, 48 \mathrm{~h}$ and $72 \mathrm{~h}$. Three independent experiments were carried out.

\section{Proliferation assay}

Transfected cells and control were seeded in 96well plates (80 000 cells/ well) and cultivated under low serum conditions (1\% FBS) for $24 \mathrm{~h}, 48 \mathrm{~h}$ and $72 \mathrm{~h}$. Viable cell number was determined on the basis of mitochondrial conversion of 3-(4,5-dimethylthiazol-2-yl)2,5-diphenyltetrazolium bromide (MTT, Sigma Aldrich, Missouri, USA) to formazine. Cells were incubated with MTT for $2 \mathrm{~h}$ at $37{ }^{\circ} \mathrm{C}$, the medium supernatant was removed and cells were lysed with sodium dodecyl sulphate for $15 \mathrm{~min}$ at room temperature. The MTT formazan crystals were dissolved with isopropanol/ $\mathrm{HCl}$ under shaking for $15 \mathrm{~min}$ at room temperature. Optical density was measured at $570 \mathrm{~nm}\left(\right.$ Synergy $^{\mathrm{TM}} 4$, BioTek, 
Winooski, USA). Each assay was executed in six-fold determination and three independent experiments were performed.

\section{Apoptosis}

Apoptotic cells were detected using YO-PRO®-1 (Thermo Fisher Scientific, Massachusetts, USA) reagent. siRNA-transfected and control cells were seeded onto 96well plates (80 000 cells/ well). After $24 \mathrm{~h}, 48 \mathrm{~h}$ and $72 \mathrm{~h}$, cells were incubated with YO-PRO ${ }^{\circ}-1$ for $15 \mathrm{~min}$ at $37^{\circ} \mathrm{C}$, the supernatant was removed, cells were washed with PBS and then measured at $485 \mathrm{~nm}$ to $535 \mathrm{~nm}$. Each assay was performed in six-fold determination and three independent experiments were carried out.

\section{Invasion assay}

For analysis of invasiveness of CRC cells, the CytoSelect TM 24-Well Cell Invasion Assay (Cell Biolabs, San Diego, USA) was performed according to the manufacturer's instructions. $1 \times 10^{5}$ siRNA transfected cells and control cells were suspended in medium with $10 \%$ FBS, placed in the upper chamber and incubated for $48 \mathrm{~h}$ at $37^{\circ} \mathrm{C}$. The cells that had invaded to the lower surface of the filter inserts were stained with crystal violet. The optical density was measured at $560 \mathrm{~nm}\left(\right.$ Synergy $^{\mathrm{TM}} 4$, BioTek, Winooski, USA).

\section{Colony forming assay}

HCT116 cells transfected with eIF1, eIF5 and eIF6 siRNA and scrambled siRNA as control were collected and seeded in six-well plates at a density of 500 cells/ well. The medium was changed every three days. After two weeks of culture, cells were washed three times with PBS and fixed in 4\% paraformaldehyde (Sigma-Aldrich, Missouri, USA). Fixed cells were stained by adding freshly prepared diluted Giemsa solution (Sigma-Aldrich, Missouri, USA) for $20 \mathrm{~min}$. Then the cells were rinsed with distilled water and colonies were analysed using a microscope (Nikon TMS - Inverted Microscope, Tokyo, Japan). Three independent experiments were carried out.

\section{Sucrose density gradient centrifugation}

Sucrose density-gradient centrifugation was performed to analyze the cellular distribution of polysomes, $80 \mathrm{~S}$ ribosomes and free $40 \mathrm{~S}$ and $60 \mathrm{~S}$ subunits. Cells were cultured in $100 \mathrm{~mm}$ dishes and transfected with siRNA and control for $24 \mathrm{~h}, 48 \mathrm{~h}$ and $72 \mathrm{~h} .15$ minutes prior to lysis, cells were incubated with $100 \mu \mathrm{g} / \mathrm{ml}$ cycloheximide (Sigma-Aldrich, Missouri, USA) to stall ribosomes on the mRNA strand. Lysis was performed on ice by washing cells in ice-cold PBS containing $100 \mu \mathrm{g} /$ $\mathrm{ml}$ cycloheximide followed by suspension in lysis buffer
(20 mM HEPES pH 7.4, $15 \mathrm{mM} \mathrm{MgCl} 2,200 \mathrm{mM} \mathrm{KCl}, 1 \%$ Triton X-100, 2mM DTT and $100 \mu \mathrm{g} / \mathrm{ml}$ cycloheximide), and nuclei were removed by centrifugation $(14000 \mathrm{~g}, 10$ $\left.\min , 4^{\circ} \mathrm{C}\right)$. The supernatant was layered onto $15 \%-40 \%$ sucrose gradients $(50 \mathrm{mM} \mathrm{NH} 4 \mathrm{Cl}, 50 \mathrm{mM}$ Tris-acetate $\mathrm{pH}$ $7.0,12 \mathrm{mM} \mathrm{MgCl} 2,100 \mu \mathrm{g} / \mathrm{ml}$ cycloheximide and freshly added $1 \mathrm{mM}$ DTT) and centrifuged in a SW41Ti rotor (Beckman, Villepinte, France) for $150 \mathrm{~min}$ at $160000 \mathrm{~g}$, $4^{\circ} \mathrm{C}$ without breaking. Sucrose density gradient profiles were analysed via an ISCO density gradient analyser unit, which analyses and simultaneously blots ribosomal distribution measured by an UA-6 detector with $254 \mathrm{~nm}$ filter (Teledyne ISCO, Nebraska, USA).

All fractions were precipitated with trichloroacetic acid overnight at $-20^{\circ} \mathrm{C}$ to concentrate proteins for gel electrophoresis.

\section{Statistical analysis}

All experimental data are represented as means \pm standard error of the mean (SEM) and were analyzed by descriptive statistics and Mann-Whitney-U-Test. Significance levels were set to $p<0.05$. All statistical analyses and graphs were generated using GraphPad Prism 4.03 software (GraphPad software Inc., La Jolla, CA, USA).

\section{CONCLUSION}

Our results emphasize the importance of separating $\mathrm{CC}$ and RC. We were able to characterize the differences in the expression pattern of mTOR members and eIFs between NNT and primary CC and RC as well as NNLT and liver metastasis derived from primary $\mathrm{CC}$ and $\mathrm{RC}$. Additionally, low and high grade tumors should be differentiated not only because of their different prognosis, but also due to their distinct molecular profiles.

In the literature, $\mathrm{CC}$ and $\mathrm{RC}$ are frequently summarized under the term CRC, but our findings indicate a probable prognostic impact when separating low and high grade $\mathrm{CC}$ and $\mathrm{RC}$.

\section{Abbreviations}

AMPK 5' adenosine monophosphate-activated protein kinase

BSA Bovine serum albumin

CC Colon carcinoma

CC Met Liver metastases of primary colon carcinoma

cDNA copy Deoxyribo-nucleic acid

CRC Colorectal carcinoma

Co2 Carbon dioxide

DMEM Dulbecco modified eagle medium

DNA Deoxyribo-nucleic acid

DTT Dithiothreitol 
4E-BP1 4E-binding protein 1

eIF Eukaryotic translation initiation factors

FBS Fetal bovine serum

GAPDH Glyceraldehyde 3-phosphate dehydrogenase

GTP Guanosine triphosphate

$\mathrm{HCl}$ Hydrochloric acid

HG High grade

HIER Heat induced epitope retrieval

IHC Immunohistochemistry

LG Low grade

LM Liver metastasis

LM TMA Liver metastasis tissue microarrays

mRNA Messenger Ribonucleic acid

miRNA Micro Ribonucleic acid

MTT 3-(4,5-dimethylthiazol-2-yl)-2,5diphenyltetrazolium bromide

mTOR Mechanistic target of rapamycin

mTORC1 Mechanistic target of rapamycin complex 1

mTORC2 Mechanistic target of rapamycin complex 2

$\mathrm{NaCl}$ Sodium chloride

NCBI National Center for Biotechnology Information

NNCRM Non-neoplastic colorectal mucosa

NNLT Non-neoplastic liver tissue

NNT Non-neoplastic colorectal mucosa tissue

PARP Poly (ADP-ribose) polymerase

PBS Phosphate buffered saline

PVDF Polyvinylidene difluoride

pRT-PCR Quantitative real-time polymerase chain reaction

$\mathrm{RC}$ Rectum carcinoma

RC Met Liver metastases of primary rectum carcinoma

RPL5 Ribosomal protein L5

RPS6 Ribosomal protein S6

RNA Ribonucleic acid

SDS Sodium dodecyl sulfate

SEM Standard error of the mean

siRNA Small interfering Ribonucleic acid

TBST Tris buffered saline with Tween

TCGA The Cancer Genome Atlas

TMA Tissue microarrays

UICC Union Internationale Contre le Cancer

WHO World Health Organization

\section{Author contributions}

NGS designed, performed and interpreted the experiments and wrote the manuscript. SK, CK and $\mathrm{CW}$ designed and interpreted biochemical analyses. CS designed and interpreted histological analyses. CK, SK, MG conducted WB and IHC analyses. NG performed sucrosegradient analyses. $\mathrm{HB}$ and $\mathrm{BP}$ designed and interpreted the sucrose gradient analysis and edited the manuscript. AMT designed and evaluated the TCGA analysis of this manuscript. AE and JF designed, performed and evaluated the in situ reactions. SU, AP, PS participating on recruiting the study patient cohort. SU, AP, PS participating on building up the study patient cohort. MK, JHO, CR and NH conceived the study, the methodology, validation and project administration. DH, CR and HL constituted the OncoTrack consortium and edited and reviewed the manuscript. $\mathrm{RS}, \mathrm{PF}$ and SL discussed experiments and interpreted data during the course of the project, and reviewed and edited the manuscript. All authors read and approved the final manuscript. JH conceived the study, designed and interpreted experiments and edited the manuscript. JH acquired funding for conducting the entire study.

\section{ACKNOWLEDGMENTS AND FUNDING}

The research leading to these results has received support from the Innovative Medicines Initiative Joint Undertaking under grant agreement $n^{\circ}$ [115234], resources of which are composed of financial contribution from the European Union's Seventh Framework Program (FP7/20072013) and EFPIA companies' in kind contribution (to J.H.).

This work was carried out with K1 COMET Competence Center CBmed, which is funded by the Federal Ministry of Transport, Innovation and Technology (BMVIT); the Federal Ministry of Science, Research and Economy (BMWFW); Land Styria (Department 12, Business and Innovation); the Styrian Business Promotion Agency (SFG); and the Vienna Business Agency. The COMET program is executed by the FFG (to J.H.). RS is funded by grants of the Austrian Science Fund (FWF P25633 and KLI 521-B31). This work was also funded by the Franz-Lanyar foundation.

We thank Daniel Kummer for his technical assistance.

\section{CONFLICTS OF INTEREST}

The authors disclose no conflicts of interest.

\section{COMPETING FINANCIAL INTERESTS}

Some of the authors are employees of commercial institutions: Eli Lilly (Christoph Reinhard), Bayer Pharma AG (David Henderson) and EPO (Jens Hoffmann, Marlen Keil). None of these companies have influenced the generation and interpretation of the data, neither do they profit financially from the publication of the results. The other authors declare no competing interests.

\section{REFERENCES}

1. Parsyan A, Hernandez G, Meterissian S. Translation initiation in colorectal cancer. Cancer Metastasis Rev. 2012; 31: 387-95. https://doi.org/10.1007/s10555-012-9349-9. 
2. Diab-Assaf M, Abou-Khouzam R, Saadallah-Zeidan N, Habib K, Bitar N, Karam W, Liagre B, Harakeh S, Azar R. Expression of eukaryotic initiation factor $4 \mathrm{E}$ and $4 \mathrm{E}$ binding protein 1 in colorectal carcinogenesis. Int J Clin Exp Pathol. 2015; 8: 404-13.

3. Wang XW, Zhang YJ. Targeting mTOR network in colorectal cancer therapy. World J Gastroenterol. 2014; 20: 4178-88. https://doi.org/10.3748/wjg.v20.i15.4178.

4. Yu X, Zheng B, Chai R. Lentivirus-mediated knockdown of eukaryotic translation initiation factor 3 subunit D inhibits proliferation of HCT116 colon cancer cells. Biosci Rep. 2014; 34: e00161. https://doi.org/10.1042/bsr20140078.

5. Watson AJ, Collins PD. Colon cancer: a civilization disorder. Dig Dis. 2011; 29: 222-8. https://doi. org/10.1159/000323926.

6. Clark ME, Smith RR. Liver-directed therapies in metastatic colorectal cancer. J Gastrointest Oncol. 2014; 5: 374-87. https://doi.org/10.3978/j.issn.2078-6891.2014.064.

7. Hohla F, Winder T, Greil R, Rick FG, Block NL, Schally AV. Targeted therapy in advanced metastatic colorectal cancer: current concepts and perspectives. World J Gastroenterol. 2014; 20: 6102-12. https://doi.org/10.3748/ wjg.v20.i20.6102.

8. Zhang W, Song T. The progress in adjuvant therapy after curative resection of liver metastasis from colorectal cancer. Drug Discov Ther. 2014; 8: 194-200.

9. Murcia O, Juarez M, Hernandez-Illan E, Egoavil C, Giner-Calabuig M, Rodriguez-Soler M, Jover R. Serrated colorectal cancer: Molecular classification, prognosis, and response to chemotherapy. World J Gastroenterol. 2016; 22: 3516-30. https://doi.org/10.3748/wjg.v22.i13.3516.

10. Pestova TV, Kolupaeva VG. The roles of individual eukaryotic translation initiation factors in ribosomal scanning and initiation codon selection. Genes Dev. 2002; 16: 2906-22. https://doi.org/10.1101/gad.1020902.

11. Clement PM, Henderson CA, Jenkins ZA, Smit-McBride Z, Wolff EC, Hershey JW, Park MH, Johansson HE. Identification and characterization of eukaryotic initiation factor 5A-2. Eur J Biochem. 2003; 270: 4254-63.

12. Tunca B, Tezcan G, Cecener G, Egeli U, Zorluoglu A, Yilmazlar T, Ak S, Yerci O, Ozturk E, Umut G, Evrensel T. Overexpression of CK20, MAP3K8 and EIF5A correlates with poor prognosis in early-onset colorectal cancer patients. J Cancer Res Clin Oncol. 2013; 139: 691-702. https://doi.org/10.1007/s00432-013-1372-x.

13. Park MH. The post-translational synthesis of a polyaminederived amino acid, hypusine, in the eukaryotic translation initiation factor 5A (eIF5A). J Biochem. 2006; 139: 161-9. https://doi.org/10.1093/jb/mvj034.

14. Rush J, Moritz A, Lee KA, Guo A, Goss VL, Spek EJ, Zhang H, Zha XM, Polakiewicz RD, Comb MJ. Immunoaffinity profiling of tyrosine phosphorylation in cancer cells. Nat Biotechnol. 2005; 23: 94-101. https://doi. org/10.1038/nbt1046.
15. Parsyan A, Svitkin Y, Shahbazian D, Gkogkas C, Lasko P, Merrick WC, Sonenberg N. mRNA helicases: the tacticians of translational control. Nat Rev Mol Cell Biol. 2011; 12 : 235-45. https://doi.org/10.1038/nrm3083.

16. Jackson RJ, Hellen CU, Pestova TV. The mechanism of eukaryotic translation initiation and principles of its regulation. Nat Rev Mol Cell Biol. 2010; 11: 113-27. https://doi.org/10.1038/nrm2838.

17. Lazaris-Karatzas A, Montine KS, Sonenberg N. Malignant transformation by a eukaryotic initiation factor subunit that binds to mRNA 5 ' cap. Nature. 1990; 345: 544-7. https:// doi.org/10.1038/345544a0.

18. Miluzio A, Beugnet A, Volta V, Biffo S. Eukaryotic initiation factor 6 mediates a continuum between $60 \mathrm{~S}$ ribosome biogenesis and translation. EMBO Rep. 2009; 10: 459-65. https://doi.org/10.1038/embor.2009.70.

19. De Marco N, Iannone L, Carotenuto R, Biffo S, Vitale A, Campanella C. p27(BBP)/eIF6 acts as an antiapoptotic factor upstream of Bcl-2 during Xenopus laevis development. Cell Death Differ. 2010; 17: 360-72. https:// doi.org/10.1038/cdd.2009.128.

20. Miluzio A, Beugnet A, Grosso S, Brina D, Mancino M, Campaner S, Amati B, de Marco A, Biffo S. Impairment of cytoplasmic eIF6 activity restricts lymphomagenesis and tumor progression without affecting normal growth. Cancer Cell. 2011; 19: 765-75. https://doi.org/10.1016/j. ccr.2011.04.018.

21. Sanvito F, Vivoli F, Gambini S, Santambrogio G, Catena M, Viale E, Veglia F, Donadini A, Biffo S, Marchisio PC. Expression of a highly conserved protein, p27BBP, during the progression of human colorectal cancer. Cancer Res. 2000; 60: 510-6.

22. Robbins CM, Tembe WA, Baker A, Sinari S, Moses TY, Beckstrom-Sternberg S, Beckstrom-Sternberg J, Barrett M, Long J, Chinnaiyan A, Lowey J, Suh E, Pearson JV, et al. Copy number and targeted mutational analysis reveals novel somatic events in metastatic prostate tumors. Genome Res. 2011; 21: 47-55. https://doi.org/10.1101/gr.107961.110.

23. Samuels Y, Wang Z, Bardelli A, Silliman N, Ptak J, Szabo S, Yan H, Gazdar A, Powell SM, Riggins GJ, Willson JK, Markowitz S, Kinzler KW, et al. High frequency of mutations of the PIK3CA gene in human cancers. Science. 2004; 304: 554. https://doi.org/10.1126/science.1096502.

24. Shahbazian D, Parsyan A, Petroulakis E, Hershey J, Sonenberg N. eIF4B controls survival and proliferation and is regulated by proto-oncogenic signaling pathways. Cell Cycle. 2010; 9: 4106-9. https://doi.org/10.4161/ cc.9.20.13630.

25. Wang Z, Chen J, Sun J, Cui Z, Wu H. RNA interferencemediated silencing of eukaryotic translation initiation factor 3, subunit B (EIF3B) gene expression inhibits proliferation of colon cancer cells. World J Surg Oncol. 2012; 10: 119. https://doi.org/10.1186/1477-7819-10-119. 
26. Liu Z, Dong Z, Yang Z, Chen Q, Pan Y, Yang Y, Cui P, Zhang X, Zhang JT. Role of eIF3a (eIF3 p170) in intestinal cell differentiation and its association with early development. Differentiation. 2007; 75: 652-61. https://doi. org/10.1111/j.1432-0436.2007.00165.x.

27. Goh SH, Hong SH, Hong SH, Lee BC, Ju MH, Jeong JS, Cho YR, Kim IH, Lee YS. eIF3m expression influences the regulation of tumorigenesis-related genes in human colon cancer. Oncogene. 2011; 30: 398-409. https://doi. org/10.1038/onc.2010.422.

28. Song N, Wang Y, Gu XD, Chen ZY, Shi LB. Effect of siRNA-mediated knockdown of eIF3c gene on survival of colon cancer cells. J Zhejiang Univ Sci B. 2013; 14: 451-9. https://doi.org/10.1631/jzus.B1200230.

29. Zeng C, Matsuda K, Jia WH, Chang J, Kweon SS, Xiang YB, Shin A, Jee SH, Kim DH, Zhang B, Cai Q, Guo X, Long J, et al. Identification of Susceptibility Loci and Genes for Colorectal Cancer Risk. Gastroenterology. 2016; 150: 1633-45. https://doi.org/10.1053/j.gastro.2016.02.076.

30. Fukuchi-Shimogori T, Ishii I, Kashiwagi K, Mashiba H, Ekimoto H, Igarashi K. Malignant transformation by overproduction of translation initiation factor eIF4G. Cancer Res. 1997; 57: 5041-4. https://doi.org/10.18632/ oncotarget.218.

31. Xu T, Zong Y, Peng L, Kong S, Zhou M, Zou J, Liu J, Miao $\mathrm{R}$, Sun X, Li L. Overexpression of eIF4E in colorectal cancer patients is associated with liver metastasis. Onco Targets Ther. 2016; 9: 815-22. https://doi.org/10.2147/ott. s98330.

32. Asano K, Clayton J, Shalev A, Hinnebusch AG. A multifactor complex of eukaryotic initiation factors, eIF1, eIF2, eIF3, eIF5, and initiator tRNA(Met) is an important translation initiation intermediate in vivo. Genes \& Development. 2000; 14: 2534-46.
33. Nielsen KH, Behrens MA, He Y, Oliveira CL, Jensen LS, Hoffmann SV, Pedersen JS, Andersen GR. Synergistic activation of eIF4A by eIF4B and eIF4G. Nucleic Acids Res. 2011; 39: 2678-89. https://doi.org/10.1093/nar/gkq1206.

34. Malina A, Cencic R, Pelletier J. Targeting translation dependence in cancer. Oncotarget. 2011; 2: 76-88. https://doi.org/10.18632/oncotarget.218.

35. Gandin V, Miluzio A, Barbieri AM, Beugnet A, Kiyokawa H, Marchisio PC, Biffo S. Eukaryotic initiation factor 6 is rate-limiting in translation, growth and transformation. Nature. 2008; 455: 684-8. https://doi.org/10.1038/ nature 07267.

36. Rosso P, Cortesina G, Sanvito F, Donadini A, Di Benedetto B, Biffo S, Marchisio PC. Overexpression of p27BBP in head and neck carcinomas and their lymph node metastases. Head Neck. 2004; 26: 408-17. https://doi.org/10.1002/ hed.10401.

37. Chendrimada TP, Finn KJ, Ji X, Baillat D, Gregory RI, Liebhaber SA, Pasquinelli AE, Shiekhattar R. MicroRNA silencing through RISC recruitment of eIF6. Nature. 2007; 447: 823-8. https://doi.org/10.1038/nature05841.

38. Yang GF, Xie D, Liu JH, Luo JH, Li LJ, Hua WF, Wu HM, Kung HF, Zeng YX, Guan XY. Expression and amplification of eIF-5A2 in human epithelial ovarian tumors and overexpression of EIF-5A2 is a new independent predictor of outcome in patients with ovarian carcinoma. Gynecol Oncol. 2009; 112: 314-8. https://doi. org/10.1016/j.ygyno.2008.10.024.

39. Conte MR, Kelly G, Babon J, Sanfelice D, Youell J, Smerdon SJ, Proud CG. Structure of the eukaryotic initiation factor (eIF) 5 reveals a fold common to several translation factors. Biochemistry. 2006; 45: 4550-8. https:// doi.org/10.1021/bi052387u. 